\title{
Skyllamycins D and E, Non-Ribosomal Cyclic Depsipeptides from Lichen Sourced Streptomyces anulatus
}

Joe Bracegirdle ${ }^{\dagger \ddagger \S}$, Peng Hou ${ }^{\ddagger \S}$, Vincent Nowak ${ }^{\ddagger \S}$, Robert A Keyzers ${ }^{\dagger \S}$, Jeremy G. Owen ${ }^{\ddagger}{ }^{\star}$

† School of Chemical and Physical Sciences, ¥ School of Biological Sciences and $\S$ Centre for Biodiscovery, Victoria University of Wellington, Wellington 6012, New Zealand.

\section{Table of Contents:}

Table S1. Organization of the skyllamycin biosynthetic gene cluster .......................................... 3

Figure S1. HPLC chromatograms $(220 \mathrm{~nm})$ of the crude extract of Streptomyces anulatus........... 5

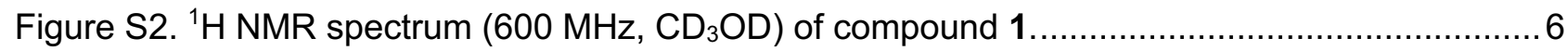

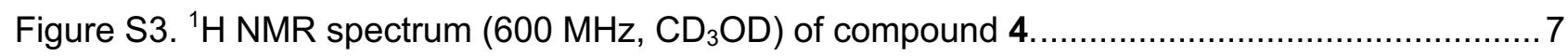

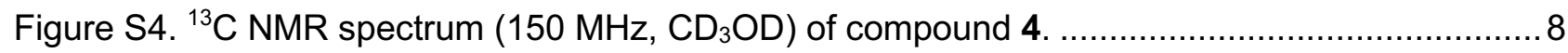

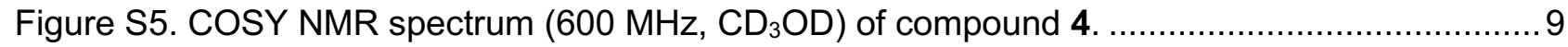

Figure S6. Multiplicity-edited HSQC NMR spectrum (600 MHz, CD3OD) of compound 4........... 10

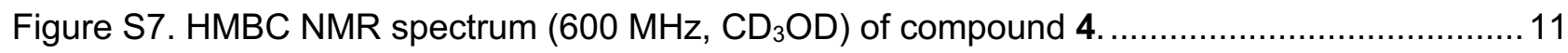

Figure S8. HSQC-TOCSY NMR spectrum (600 MHz, CD $\left.{ }_{3} \mathrm{OD}\right)$ of compound 4....................... 12

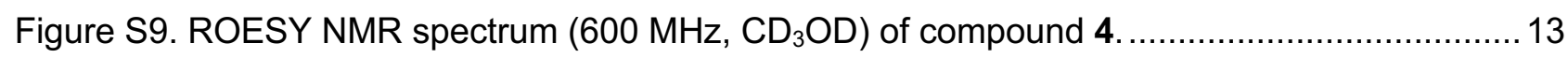

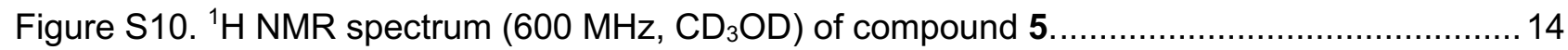

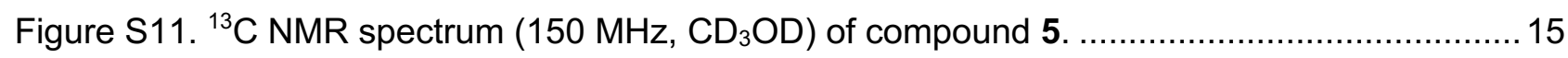

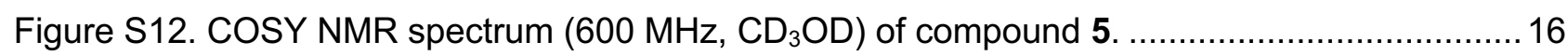

Figure S13. Multiplicity-edited HSQC NMR spectrum (600 MHz, $\mathrm{CD}_{3} \mathrm{OD}$ ) of compound 5..........17

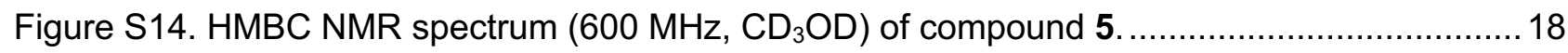

Figure S15. HSQC-TOCSY NMR spectrum (600 MHz, CD $\left.{ }_{3} \mathrm{OD}\right)$ of compound 5.....................19

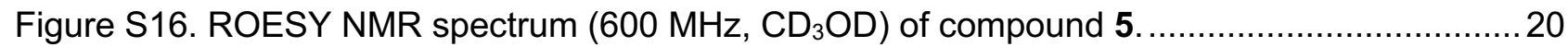

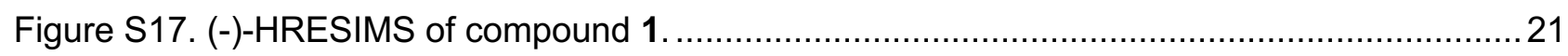

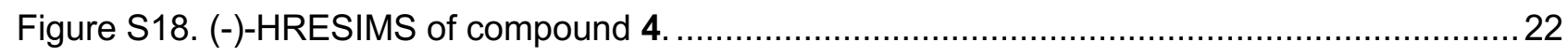

Figure S19. (+)-HRESIMS/MS of compound 6 (hydrolyzed compound 4), .................................22

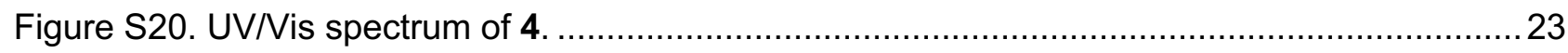


Figure S21. (-)-HRESIMS of compound 5.

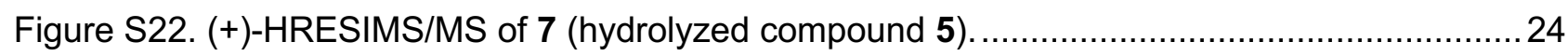

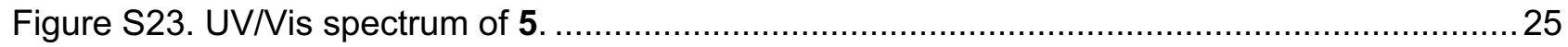

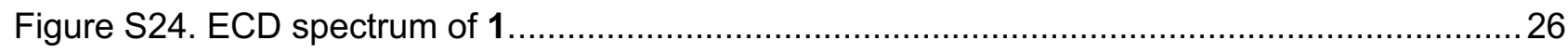

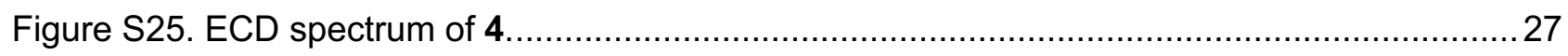

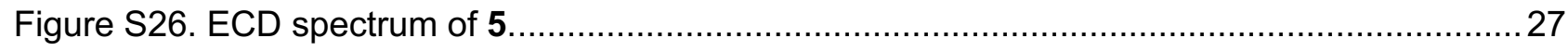


Table S1. Organization of the skyllamycin biosynthetic gene cluster (sky).

\begin{tabular}{|c|c|c|c|}
\hline orf & Size(aa) & $\begin{array}{c}\text { Skyllamycin } \\
\text { homologue } \\
\text { (\% aa identity) }\end{array}$ & Proposed Function \\
\hline ctg1_3833 & 84 & ORF49 (97.619) & putative DNA polymerase III \\
\hline $\operatorname{ctg} 1 \_3834$ & 490 & sky48 (89.764) & putative DNA-binding protein \\
\hline $\operatorname{ctg} 1 \_3835$ & 236 & absent & 4'-phosphopantetheinyl transferase superfamily protein \\
\hline $\operatorname{ctg} 1 \_3836$ & 270 & sky47 (99.24) & putative LuxR-family transcriptional regulator \\
\hline $\operatorname{ctg} 1 \_3837$ & 312 & sky46 (98.921) & putative LuxR-family transcriptional regulator \\
\hline $\operatorname{ctg} 1 \_3838$ & 243 & sky45 (98.667) & putative IcIR-family transcriptional regulator \\
\hline ctg1_3839 & 647 & sky44 (97.991) & putative AfsR-like transcriptional regulator \\
\hline $\operatorname{ctg} 1 \_3840$ & 69 & absent & hypothetical protein \\
\hline ctg1_3841 & 243 & sky43 (99.588) & putative IcIR-family transcriptional regulator \\
\hline $\operatorname{ctg} 1 \_3842$ & 94 & absent & LysR family transcriptional regulator \\
\hline ctg1_3843 & 166 & sky42 (98.077) & glutamate mutase subunit $A$ \\
\hline $\operatorname{ctg} 1 \_3844$ & 438 & sky41 (99.315) & glutamate mutase subunit $B$ \\
\hline $\operatorname{ctg} 1 \_3845$ & 174 & sky40 (99.425) & putative flavin reductase \\
\hline $\operatorname{ctg} 1 \_3846$ & 356 & sky39 (98.596) & flavin-dependent monooxygenase \\
\hline $\operatorname{ctg} 1 \_3847$ & 264 & sky38 (99.242) & putative $\mathrm{ABC}$ transporter \\
\hline ctg1_3848 & 383 & sky37 (99.708) & O-methyltransferase \\
\hline $\operatorname{ctg} 1 \_3849$ & 262 & sky36 (99.617) & putative $A B C$ transporter \\
\hline ctg1_3850 & 325 & sky35 (99.692) & putative $A B C$ transporter \\
\hline ctg1_3851 & 218 & ORF34 (98.844) & hypothetical protein \\
\hline ctg1_3852 & 257 & sky33 (98.054) & putative type II thioesterase \\
\hline $\operatorname{ctg} 1 \_3853$ & 423 & sky32 (99.527) & P450 monooxygenase \\
\hline ctg1_3854 & 3908 & sky31 (97.954) & peptide synthetase \\
\hline ctg1_3855 & 4728 & sky30 (98.837) & peptide synthetase \\
\hline $\operatorname{ctg} 1 \_3856$ & 4747 & sky29 (98.799) & peptide synthetase \\
\hline ctg1_3857 & 555 & sky28 (99.64) & putative oxidoreductase \\
\hline $\operatorname{ctg} 1 \_3858$ & 236 & sky27 (98.729) & putative isomerase \\
\hline ctg1_3859 & 248 & sky26 (99.597) & putative 3-oxoacyl-ACP reductase \\
\hline $\operatorname{ctg} 1 \_3860$ & 162 & sky25 (98.148) & putative 3-hydroxyacyl-ACP dehydratase \\
\hline $\operatorname{ctg} 1 \_3861$ & 148 & sky24 (98.45) & putative dehydratase \\
\hline $\operatorname{ctg} 1 \_3862$ & 87 & sky23 (100) & putative acyl carrier protein \\
\hline $\operatorname{ctg} 1 \_3863$ & 367 & sky22 (99.728) & putative 3-oxoacyl-ACP synthase I \\
\hline $\operatorname{ctg} 1 \_3864$ & 346 & sky21 (99.711) & putative thioesterase \\
\hline $\operatorname{ctg} 1 \_3865$ & 296 & sky20 (95.357) & putative hydrolase \\
\hline ctg1_3866 & 320 & sky19 (97.188) & putative 3-oxoacyl-ACP synthase I \\
\hline $\operatorname{ctg} 1 \_3867$ & 377 & sky18 (98.939) & putative 3-oxoacyl-ACP synthase II \\
\hline ctg1_3868 & 418 & sky17 (99.761) & putative 3-oxoacyl-ACP synthase II \\
\hline $\operatorname{ctg} 1 \_3869$ & 84 & sky16 (100) & putative acyl carrier protein \\
\hline ctg1_3870 & 73 & sky15 (100) & putative $\mathrm{MbtH}$-like protein \\
\hline $\operatorname{ctg} 1 \_3871$ & 653 & sky14 (99.847) & putative $A B C 1$-family protein kinase \\
\hline ctg1_3872 & 286 & sky13 (99.65) & putative ACP-acyltransferase \\
\hline ctg1_3873 & 347 & ORF12 (99.135) & putative isoprenyl diphosphate synthase \\
\hline $\operatorname{ctg} 1 \_3874$ & 515 & sky11 (100) & putative carboxyltransferase \\
\hline ctg1_3875 & 70 & absent & hypothetical protein \\
\hline $\operatorname{ctg} 1 \_3876$ & 478 & ORF10 (86.275) & putative integrin-like protein \\
\hline $\operatorname{ctg} 1 \_3877$ & 78 & absent & DUF397 domain-containing protein \\
\hline $\operatorname{ctg} 1 \_3878$ & 278 & sky8 (90.647) & putative DNA-binding protein \\
\hline ctg1_3879 & 135 & ORF7 (96.296) & hypothetical protein \\
\hline
\end{tabular}




\begin{tabular}{llcc} 
ctg1_3880 & 205 & sky6 $(91.22)$ & putative N-acetyltransferase \\
ctg1_3881 & 218 & sky5 $(96.789)$ & putative isomerase \\
ctg1_3882 & 376 & sky4 $(98.383)$ & putative oxidoreductase \\
ctg1_3883 & 159 & ORF3 (100) & putative cytosine/adenosine deaminase \\
ctg1_3884 & 106 & sky2 $(99.057)$ & putative SMR-type multi-drug efflux transporter \\
ctg1_3885 & 137 & sky1 $(100)$ & putative SMR-type multi-drug efflux transporter \\
\hline
\end{tabular}


Figure S1. HPLC chromatograms $(220 \mathrm{~nm})$ from crude MeOH extract of $S$. anulatus mycelium.
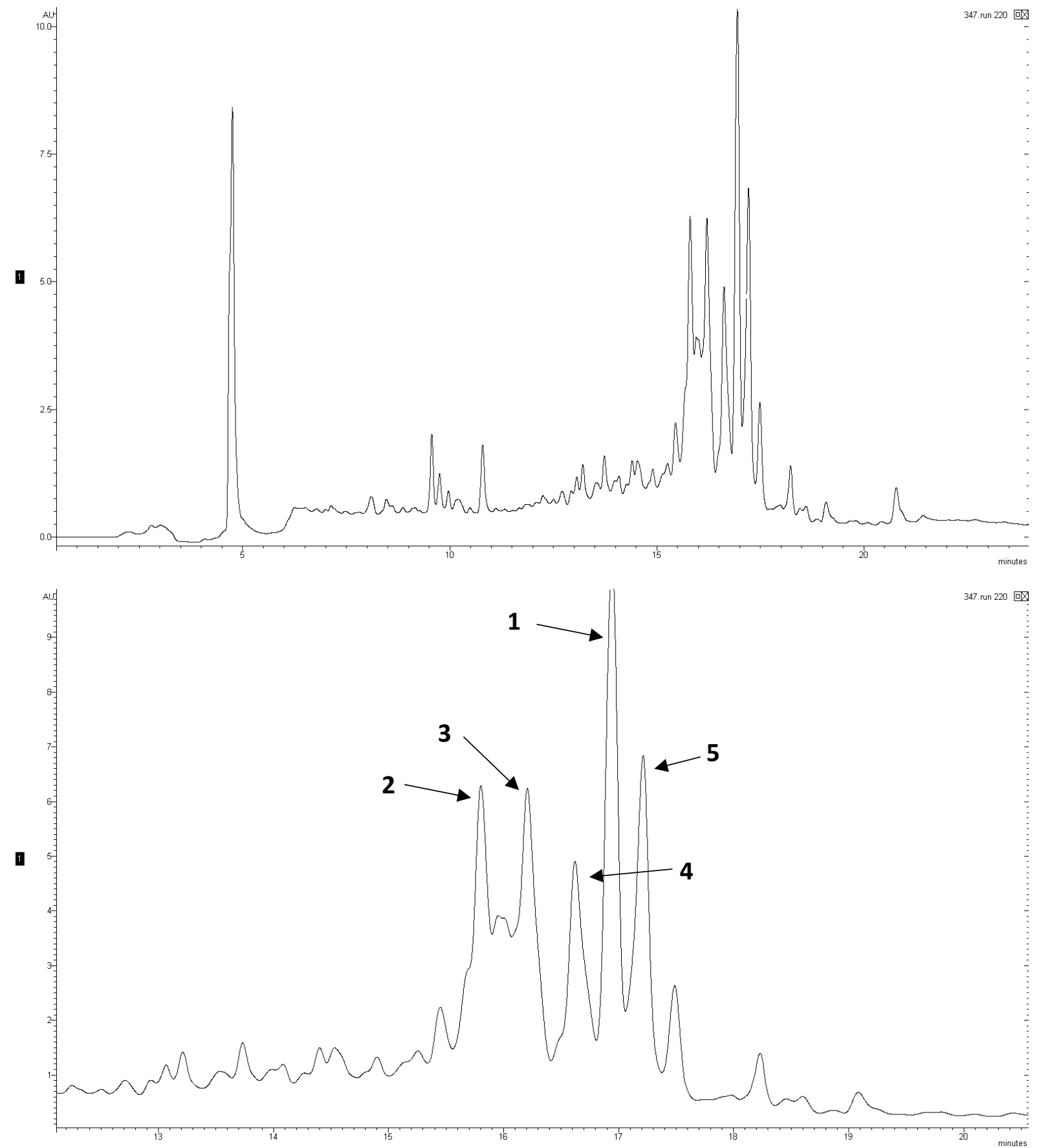
Figure S2. ${ }^{1} \mathrm{H}$ NMR spectrum $\left(600 \mathrm{MHz}, \mathrm{CD}_{3} \mathrm{OD}\right.$ ) of compound 1.

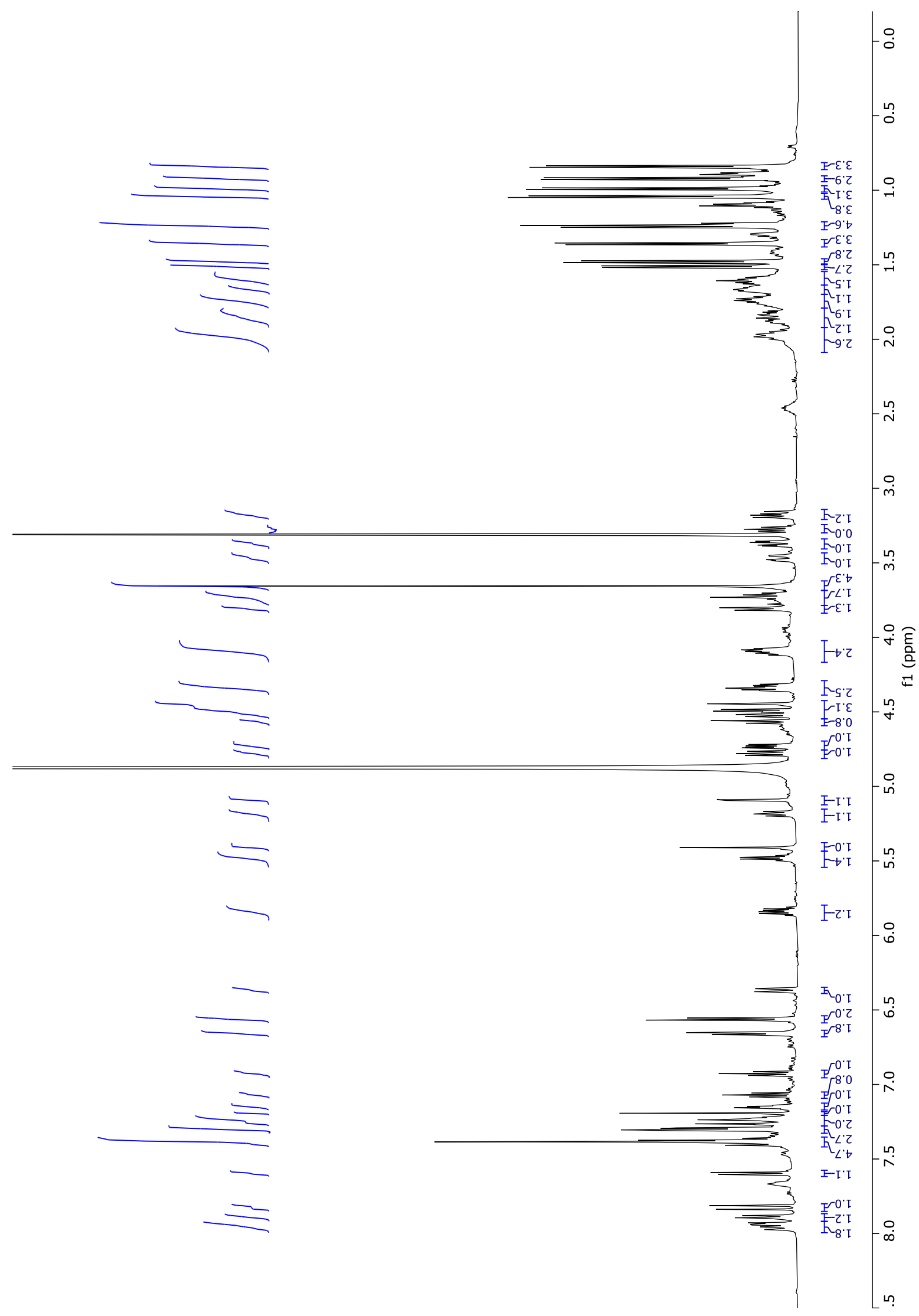


Figure S3. ${ }^{1} \mathrm{H}$ NMR spectrum $\left(600 \mathrm{MHz}, \mathrm{CD}_{3} \mathrm{OD}\right)$ of compound 4 .

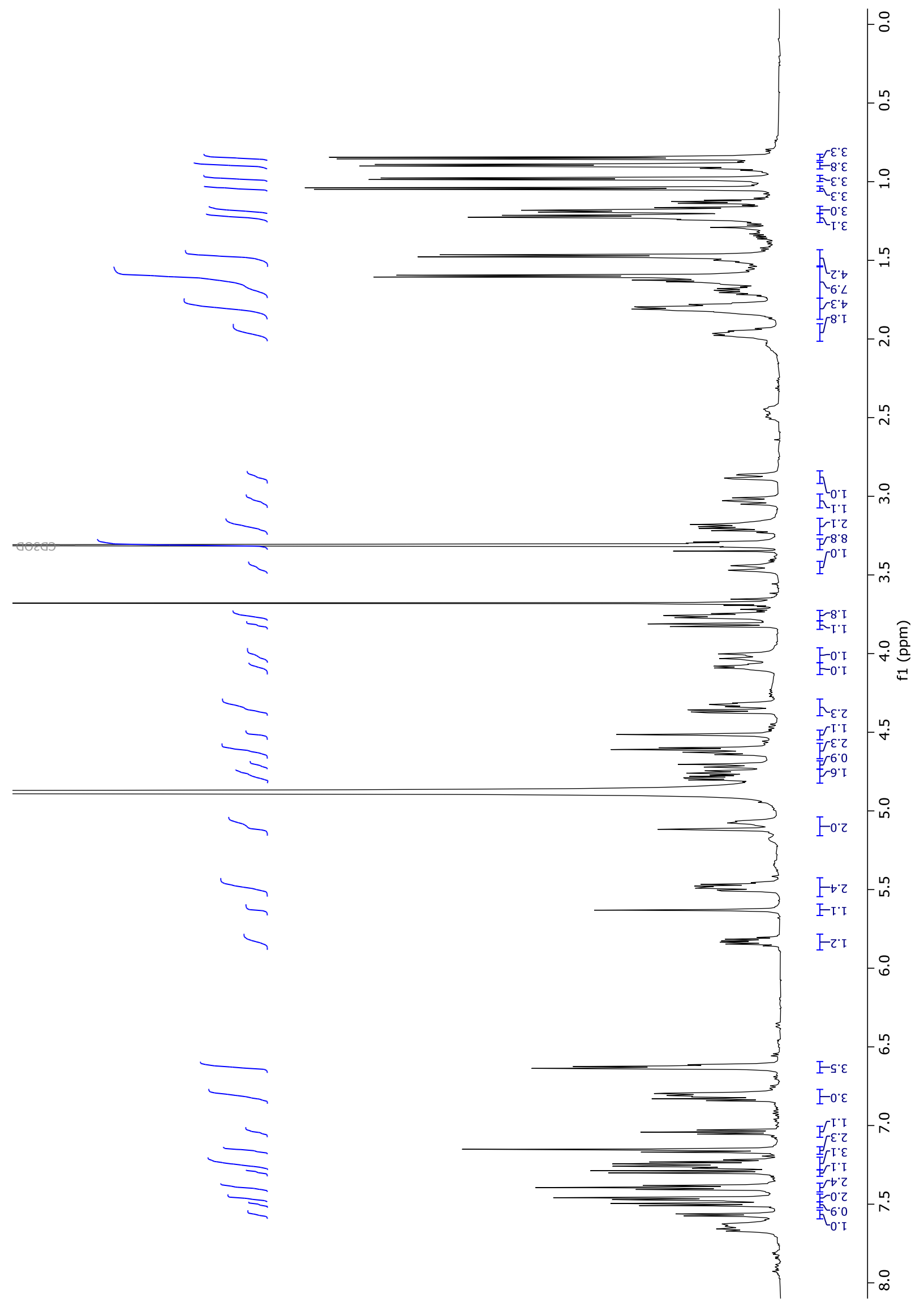


Figure S4. ${ }^{13} \mathrm{C}$ NMR spectrum $\left(150 \mathrm{MHz}, \mathrm{CD}_{3} \mathrm{OD}\right)$ of compound 4 .

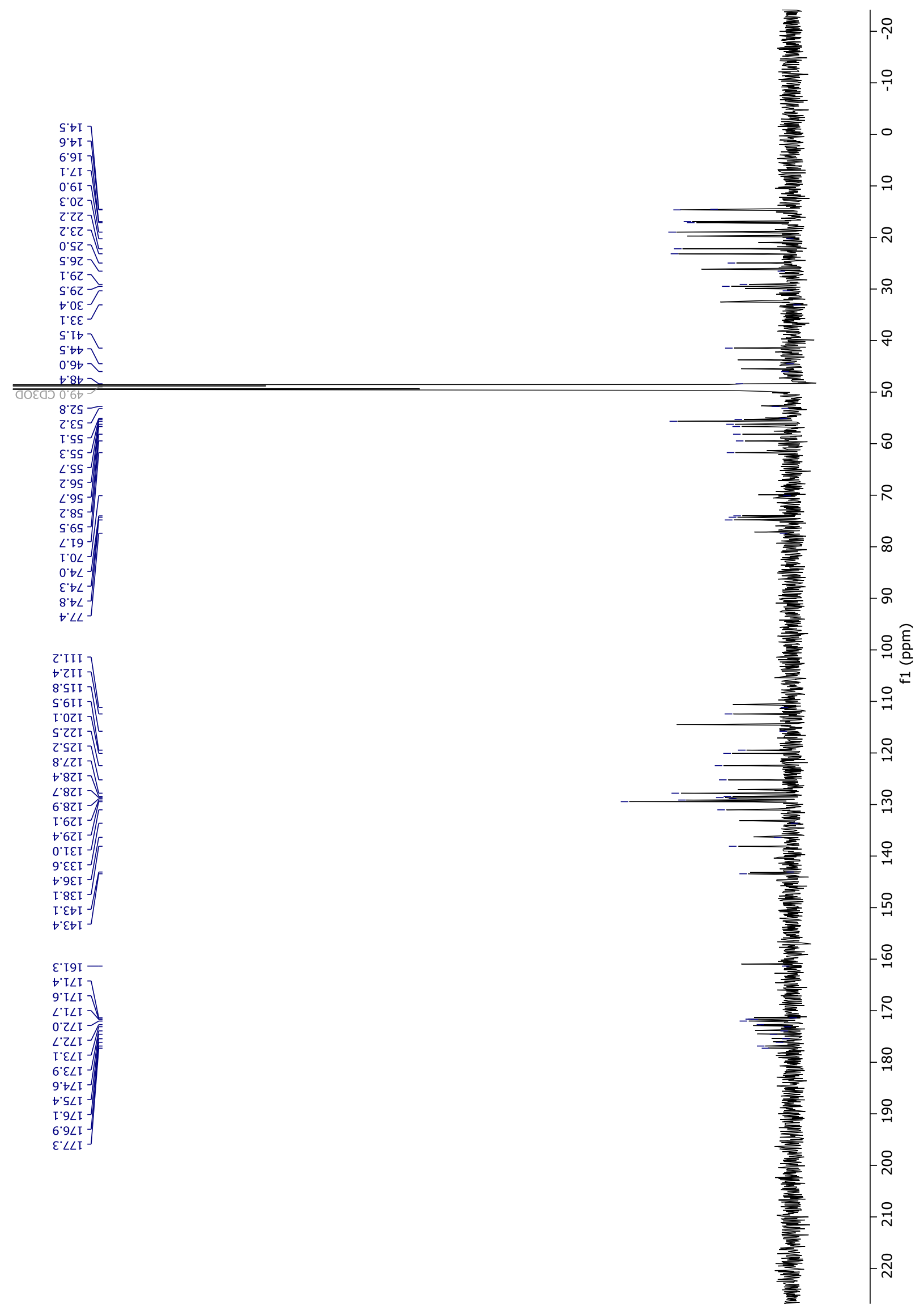


Figure S5. COSY NMR spectrum (600 MHz, CD $\left.{ }_{3} \mathrm{OD}\right)$ of compound 4.

(udd) It

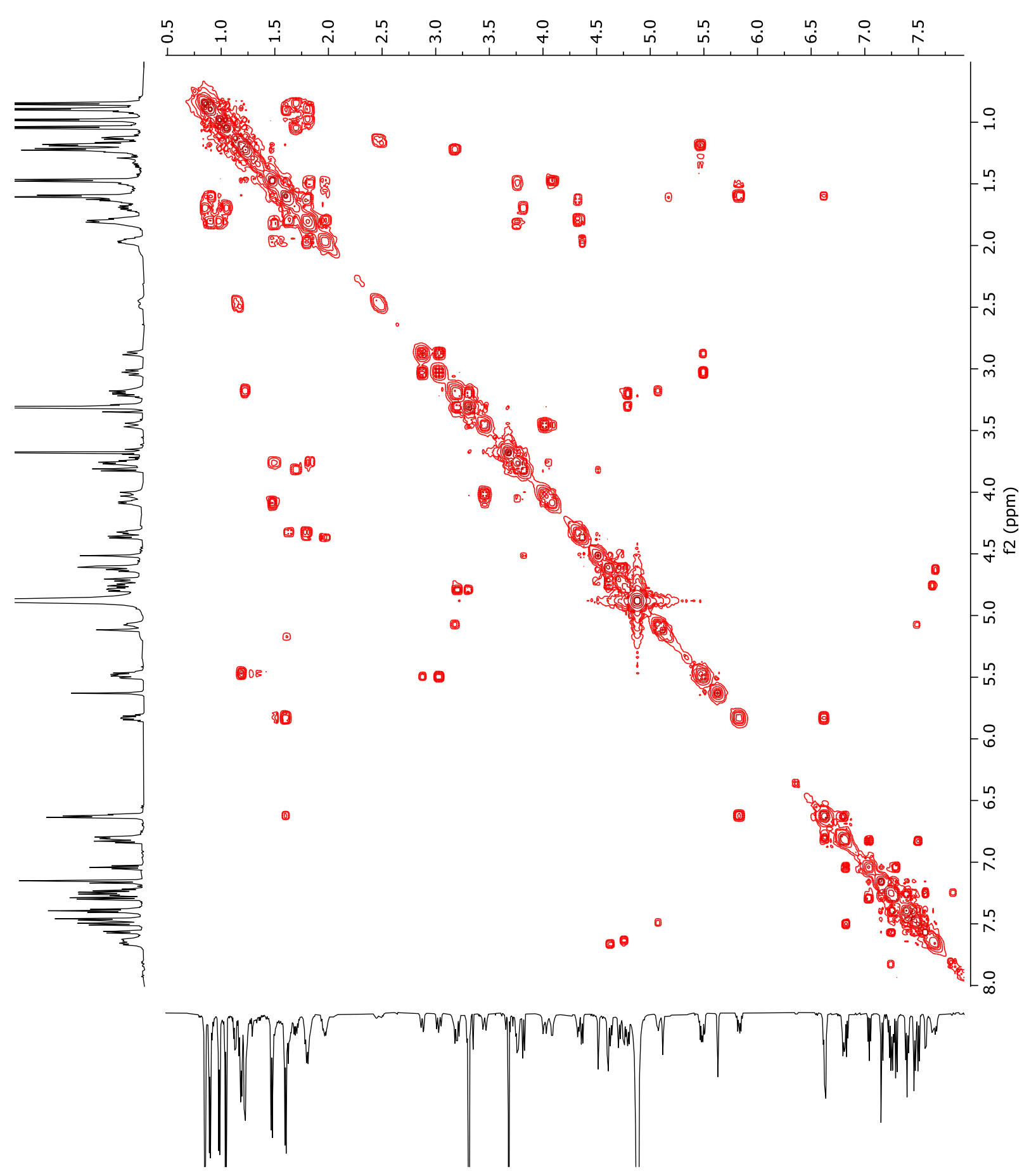


Figure S6. Multiplicity-edited HSQC NMR spectrum (600 MHz, CD3OD) of compound 4.

(udd) It

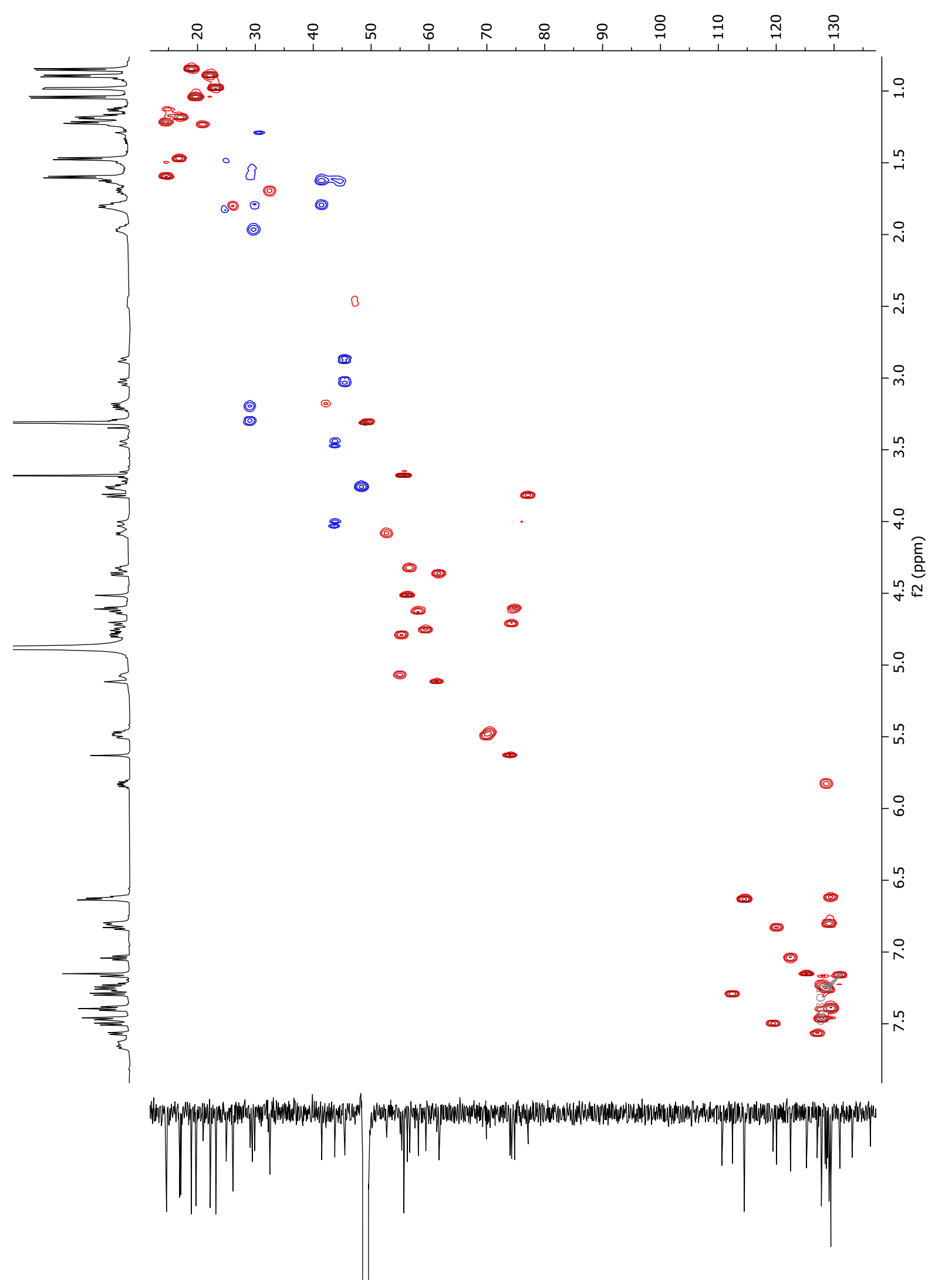


Figure S7. HMBC NMR spectrum (600 MHz, CD $\left.{ }_{3} \mathrm{OD}\right)$ of compound 4.

(udd) it
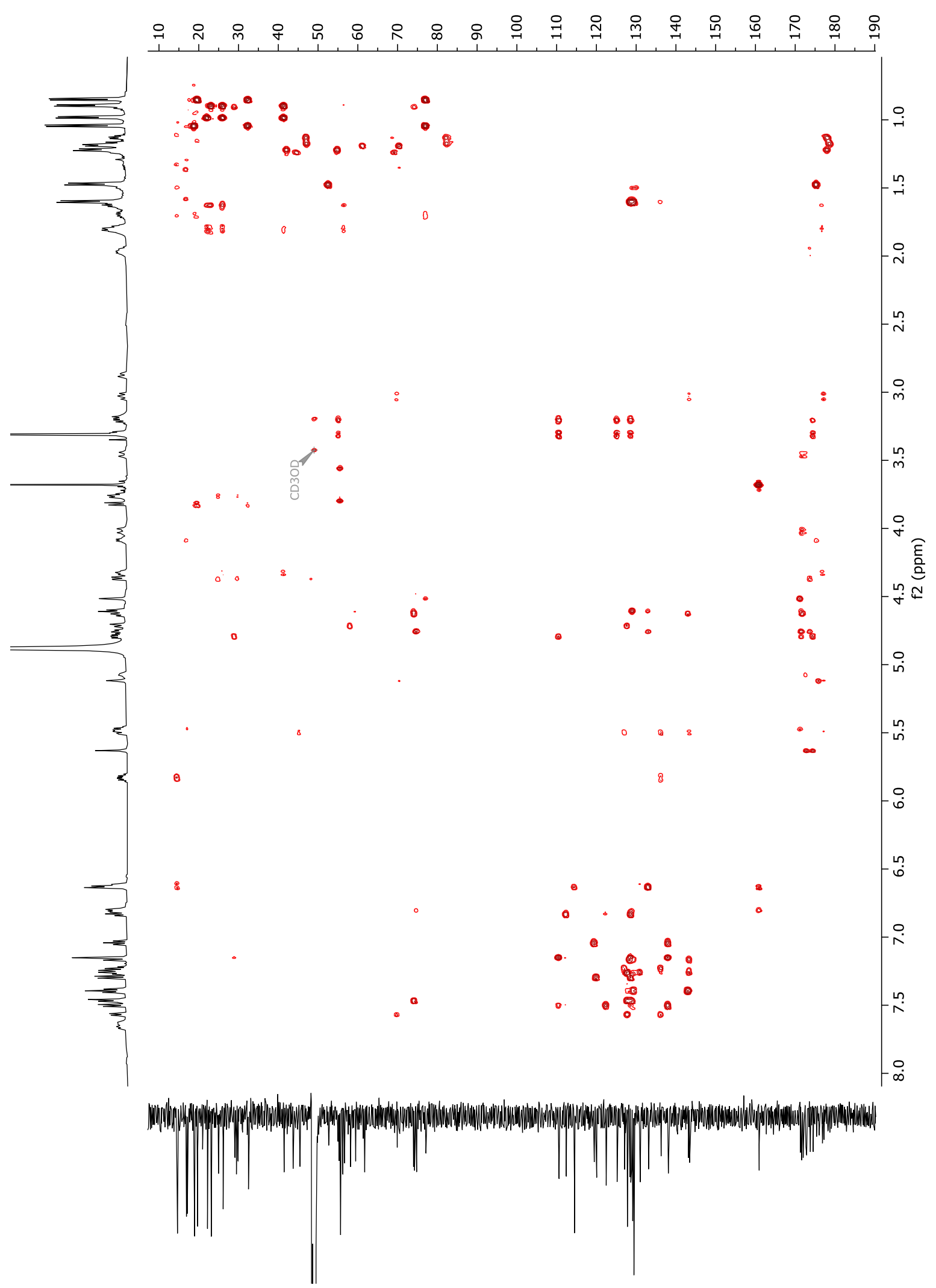
Figure S8. HSQC-TOCSY NMR spectrum (600 MHz, CD $\mathrm{CDD}_{3} \mathrm{O}$ ) of compound 4.

(udd) it
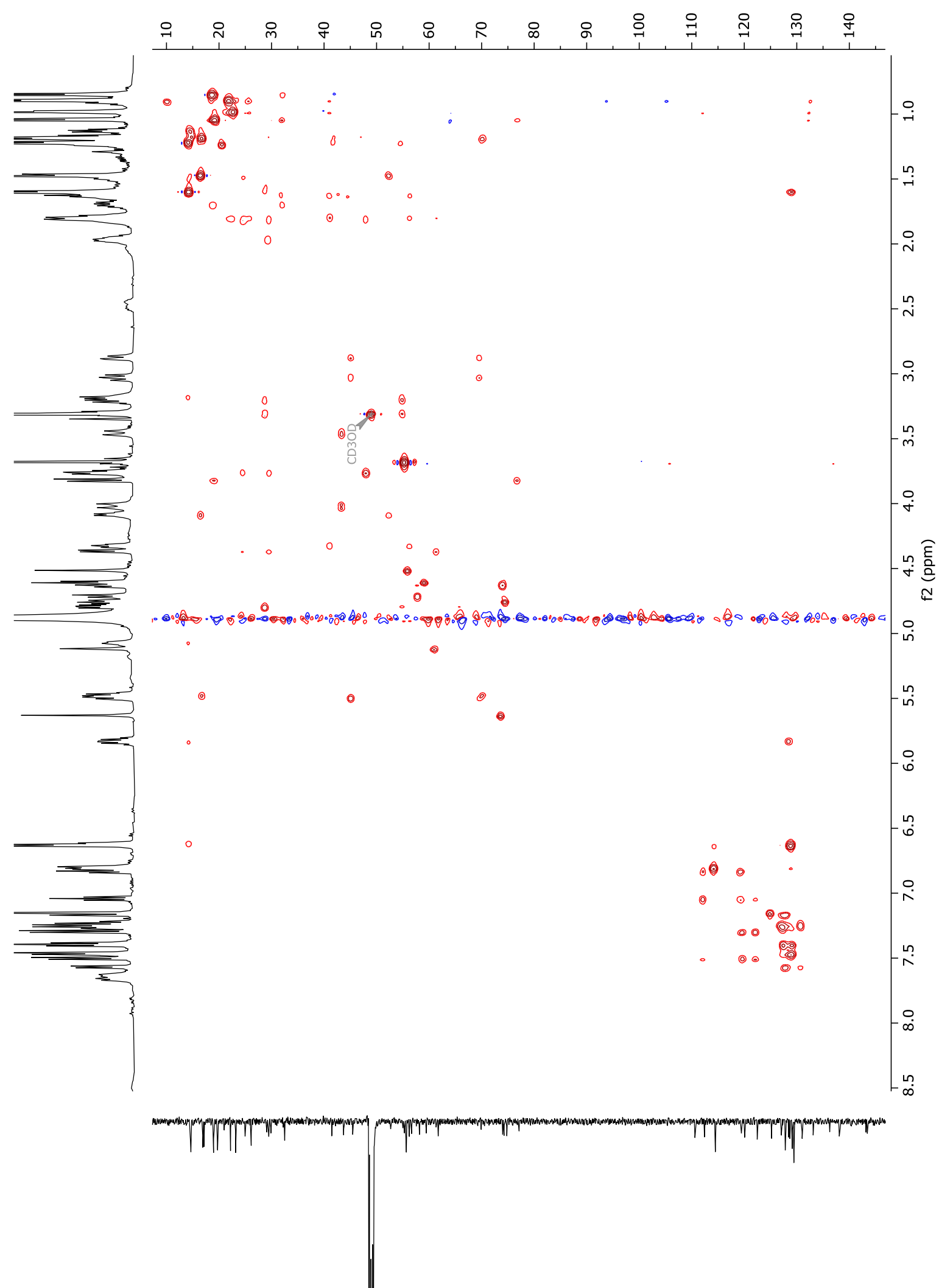
Figure S9. ROESY NMR spectrum (600 MHz, CD $\left.{ }_{3} \mathrm{OD}\right)$ of compound 4.

(udd) If

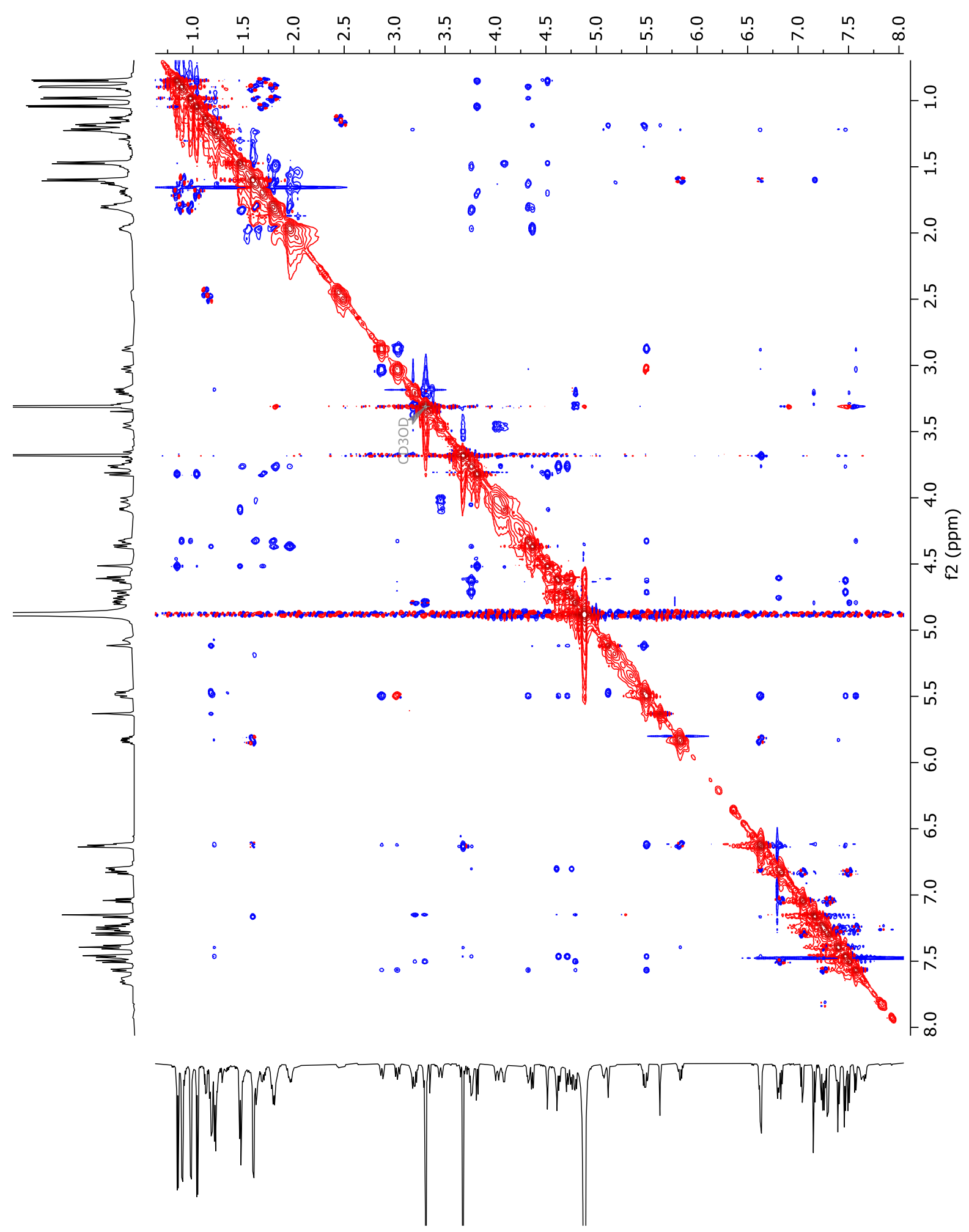


Figure $\mathrm{S} 10 .{ }^{1} \mathrm{H}$ NMR spectrum $\left(600 \mathrm{MHz}, \mathrm{CD}_{3} \mathrm{OD}\right)$ of compound $\mathbf{5}$.

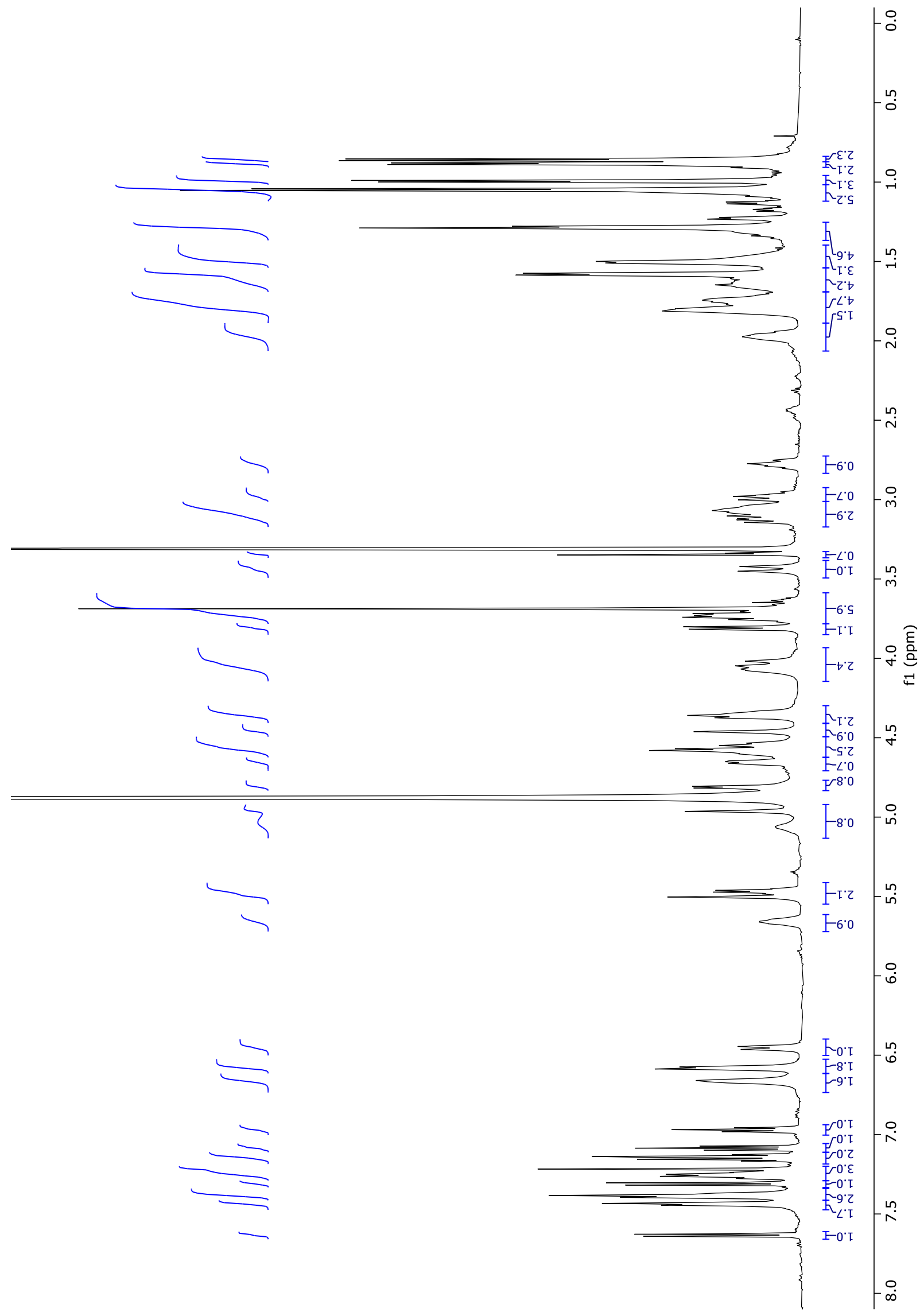


Figure S11. ${ }^{13} \mathrm{C}$ NMR spectrum $\left(150 \mathrm{MHz}, \mathrm{CD}_{3} \mathrm{OD}\right)$ of compound $\mathbf{5}$.
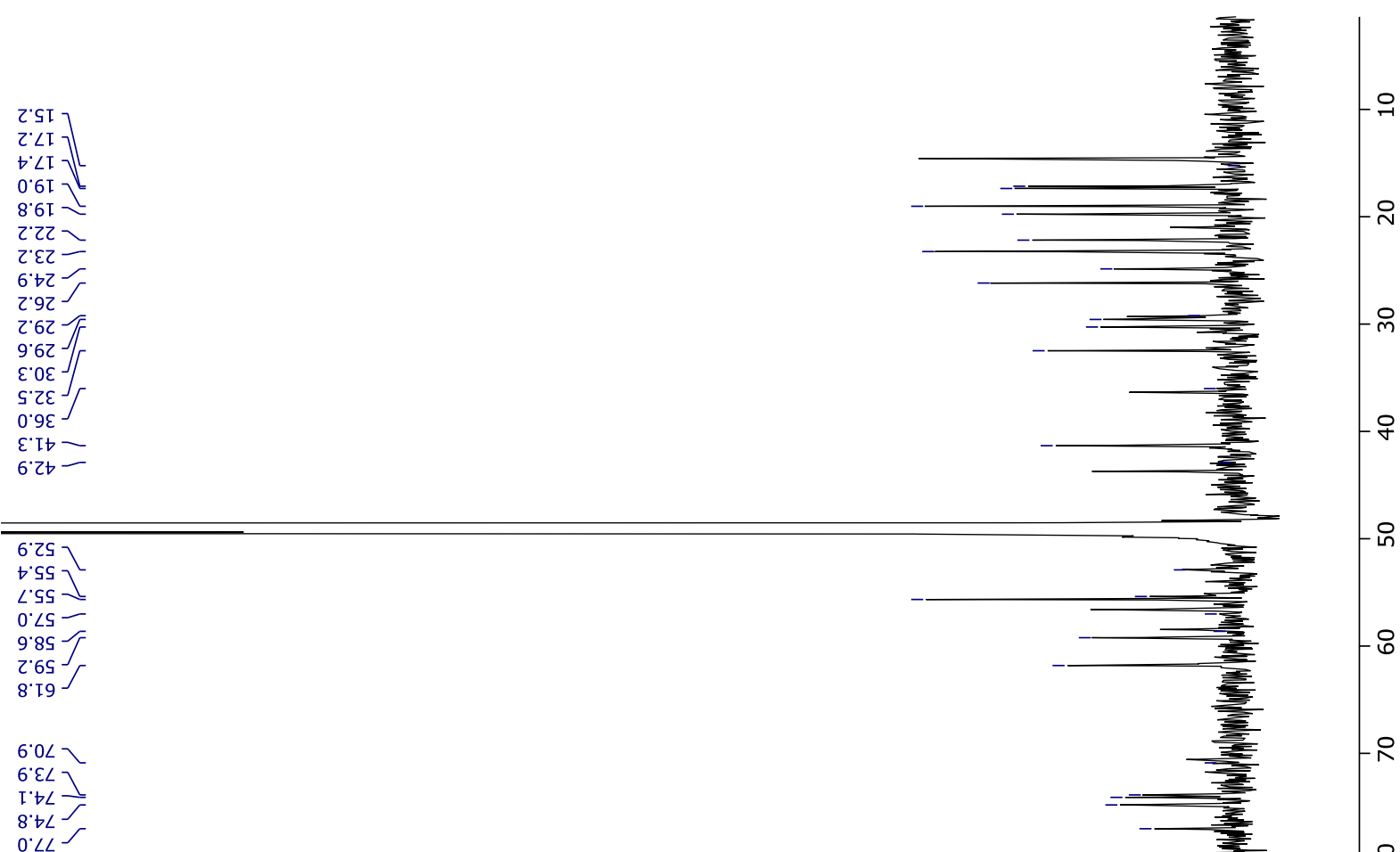

Z. III

$\left.\begin{array}{l}8 \text { 'ZI } \\ \text { S'SII }\end{array}\right]$

$\angle$ 6II

$\rightarrow$ OZI

$0 . \varepsilon Z[$

$8 . \mathrm{SZI}$

$\angle \cdot 9 Z[$

$9 \cdot \angle Z T$

s.8ZI

$\angle 8 Z \mathrm{I}$

2.62I

$t .62 I$

$9.62 \mathrm{I}$

$9.0 \varepsilon[$

$6 \cdot \varepsilon \varepsilon \mathrm{I}$

$\angle$ 'LEI

$9.8 \varepsilon[$

[' โ七I ]

E'StI

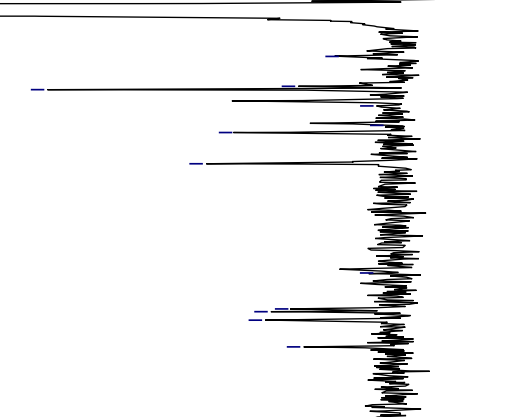

오

$-8$

-

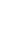

흥

$\stackrel{-}{-1}$

용

ิำ

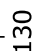

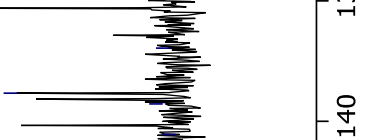

0.โ9โ -

t. $T \angle I$

5. $[\angle I]$

$6 \cdot 2 \angle 1$

¿' $\varepsilon \angle I$

¿हL

$0 \times \square \angle I$

$\left.\begin{array}{l}\angle ' b \angle I \\ \varepsilon \cdot \angle L I\end{array}\right]$

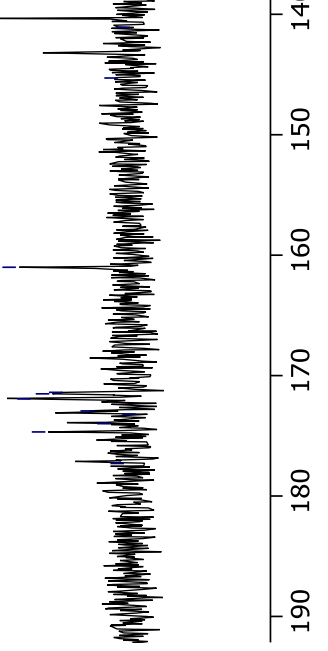


Figure S12. COSY NMR spectrum ( $600 \mathrm{MHz}, \mathrm{CD}_{3} \mathrm{OD}$ ) of compound $\mathbf{5}$.

(mdd) If
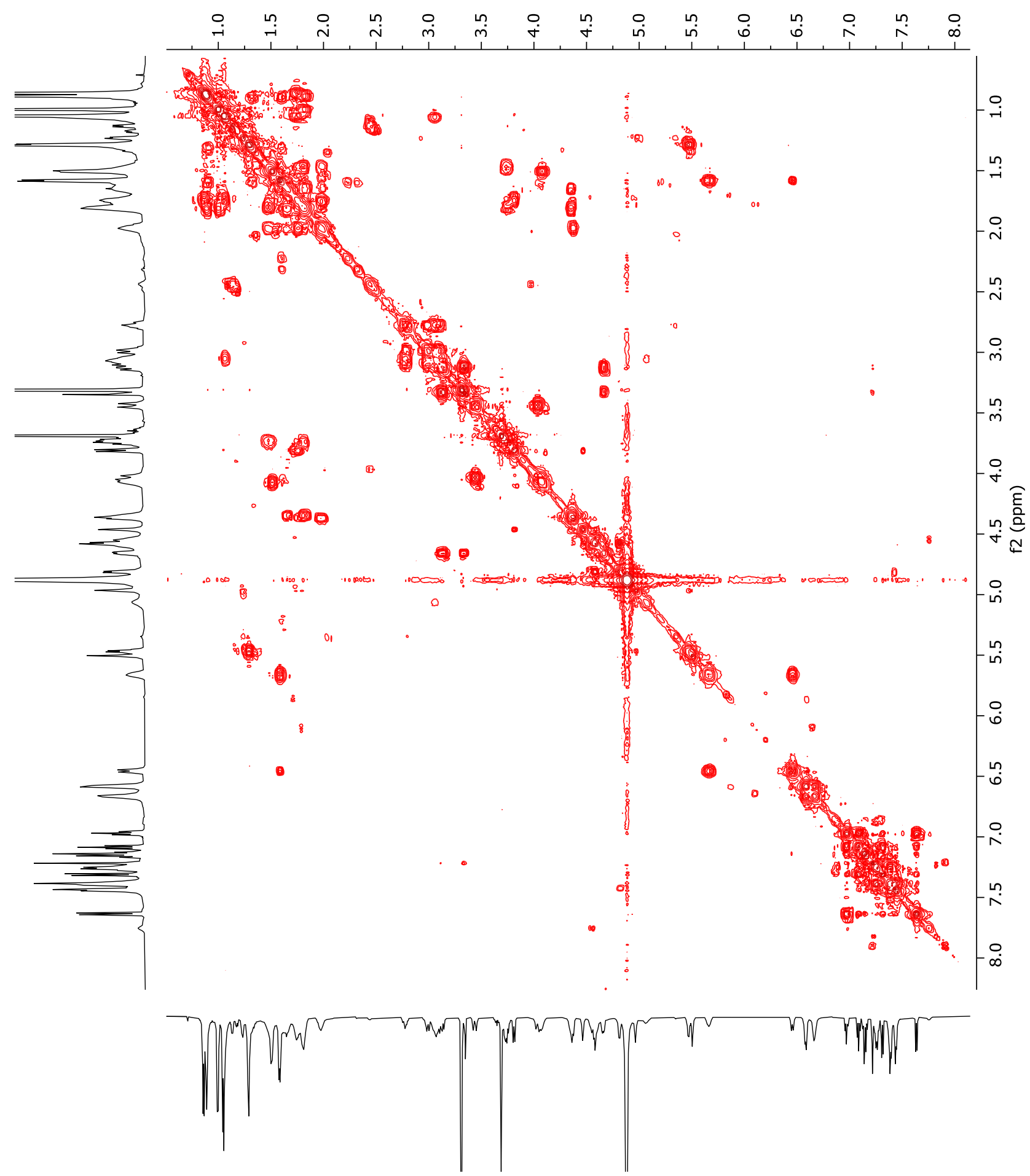
Figure S13. Multiplicity-edited HSQC NMR spectrum (600 MHz, $\left.\mathrm{CD}_{3} \mathrm{OD}\right)$ of compound 5.

(udd) If

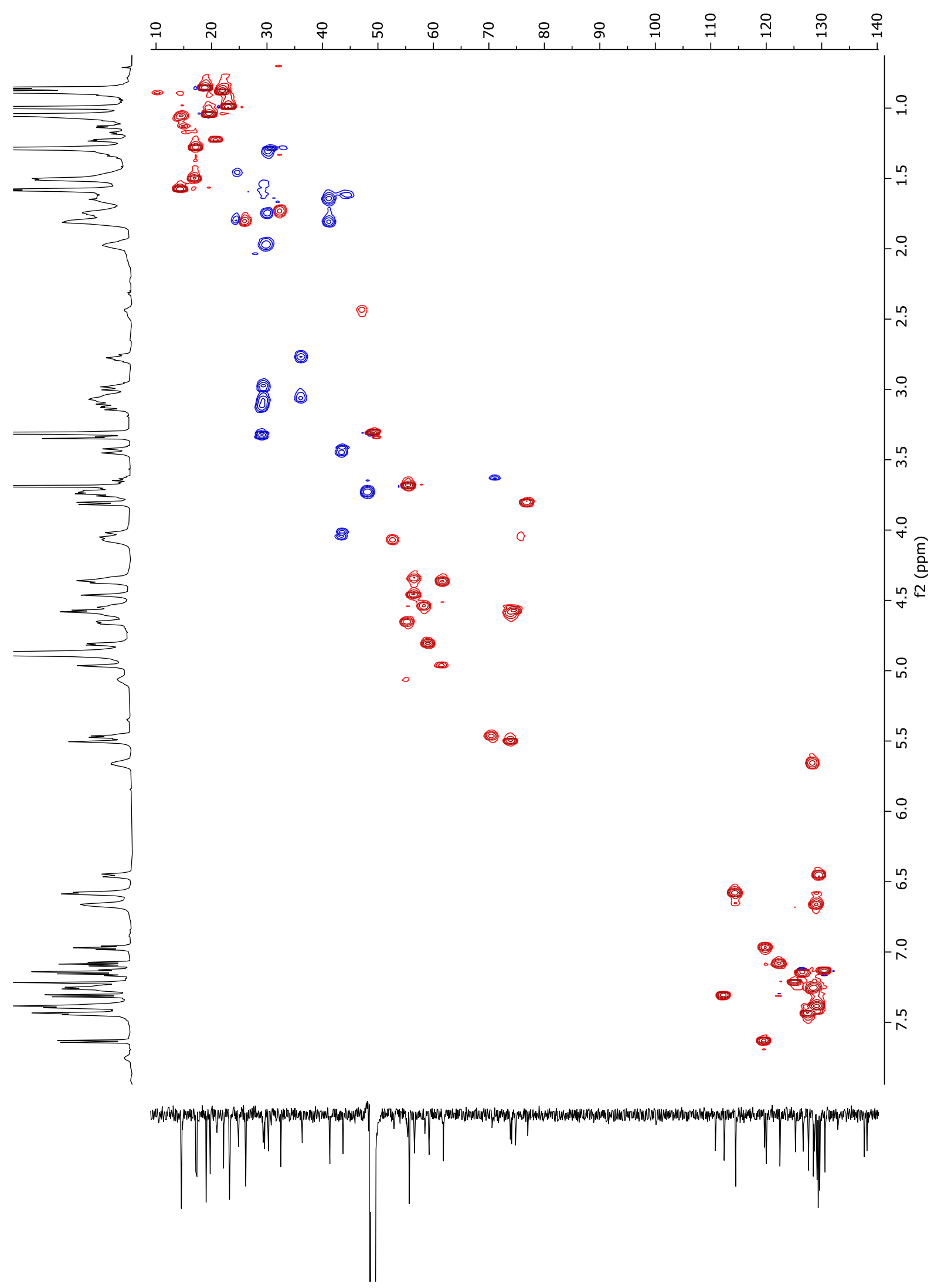


Figure S14. HMBC NMR spectrum (600 MHz, CD $\left.{ }_{3} \mathrm{OD}\right)$ of compound 5.

(udd) if
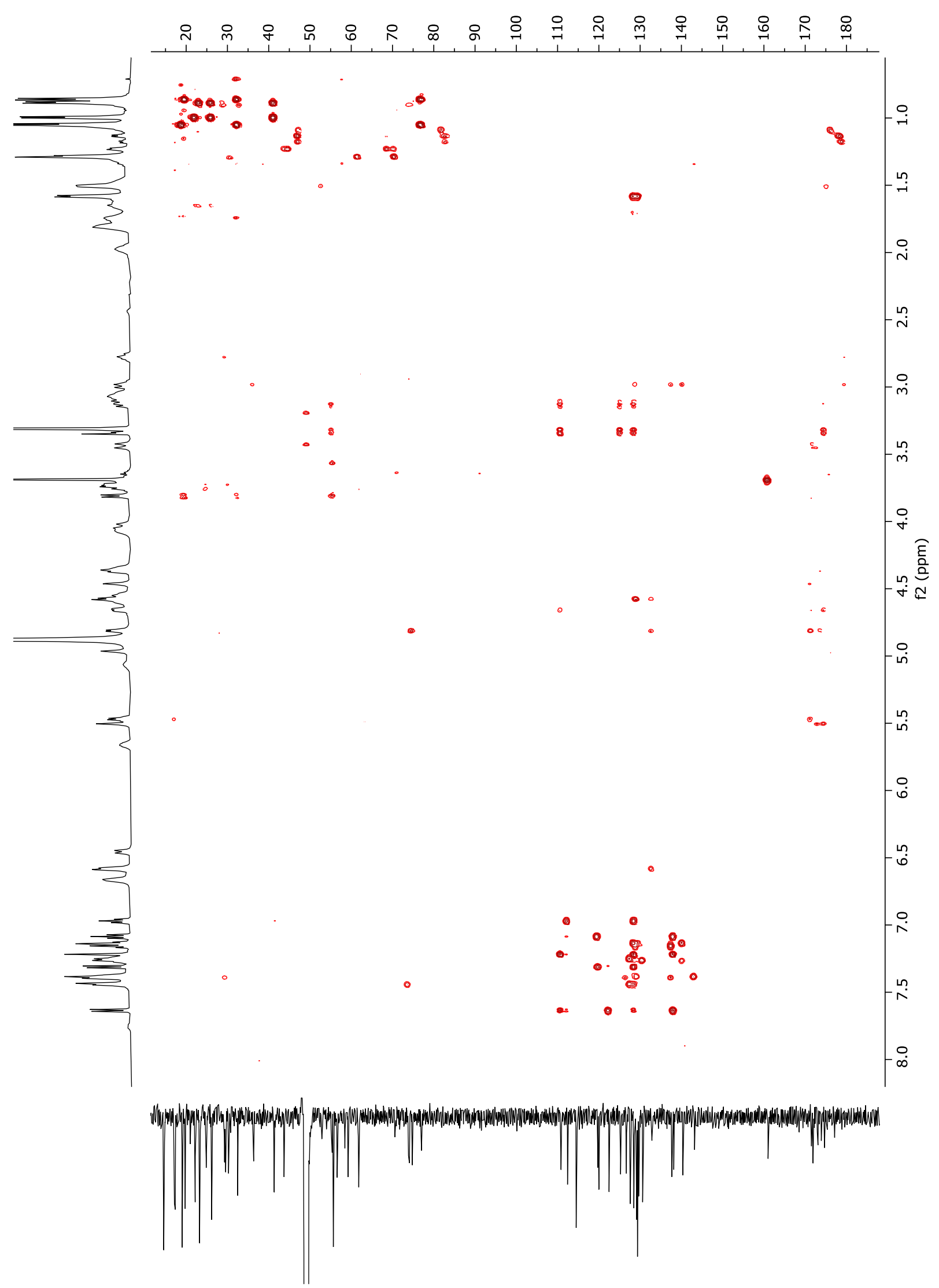
Figure S15. HSQC-TOCSY NMR spectrum (600 MHz, CD $\left.{ }_{3} \mathrm{OD}\right)$ of compound 5.

(udd) it

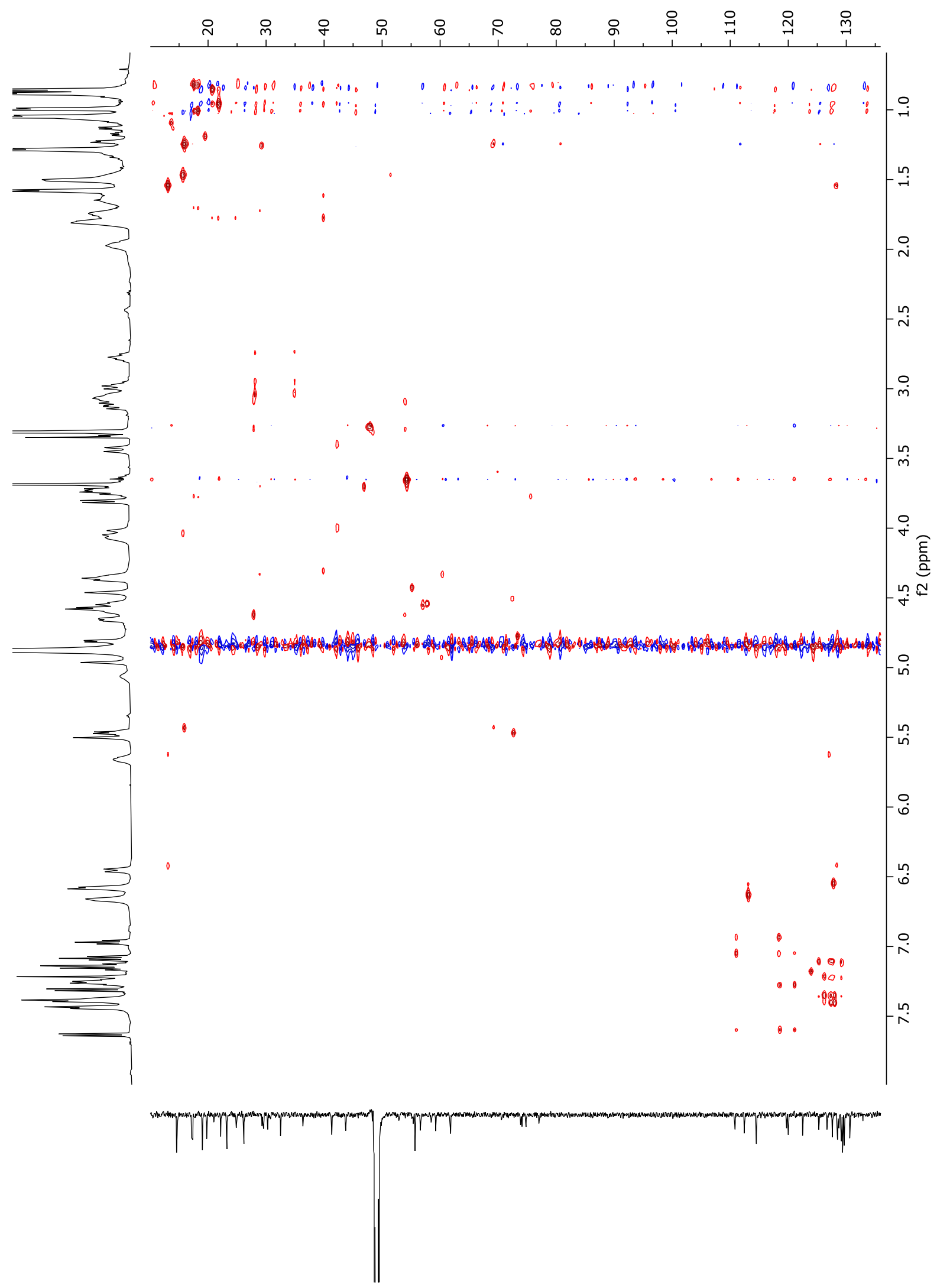


Figure S16. ROESY NMR spectrum (600 MHz, $\left.\mathrm{CD}_{3} \mathrm{OD}\right)$ of compound 5 .

(udd) It

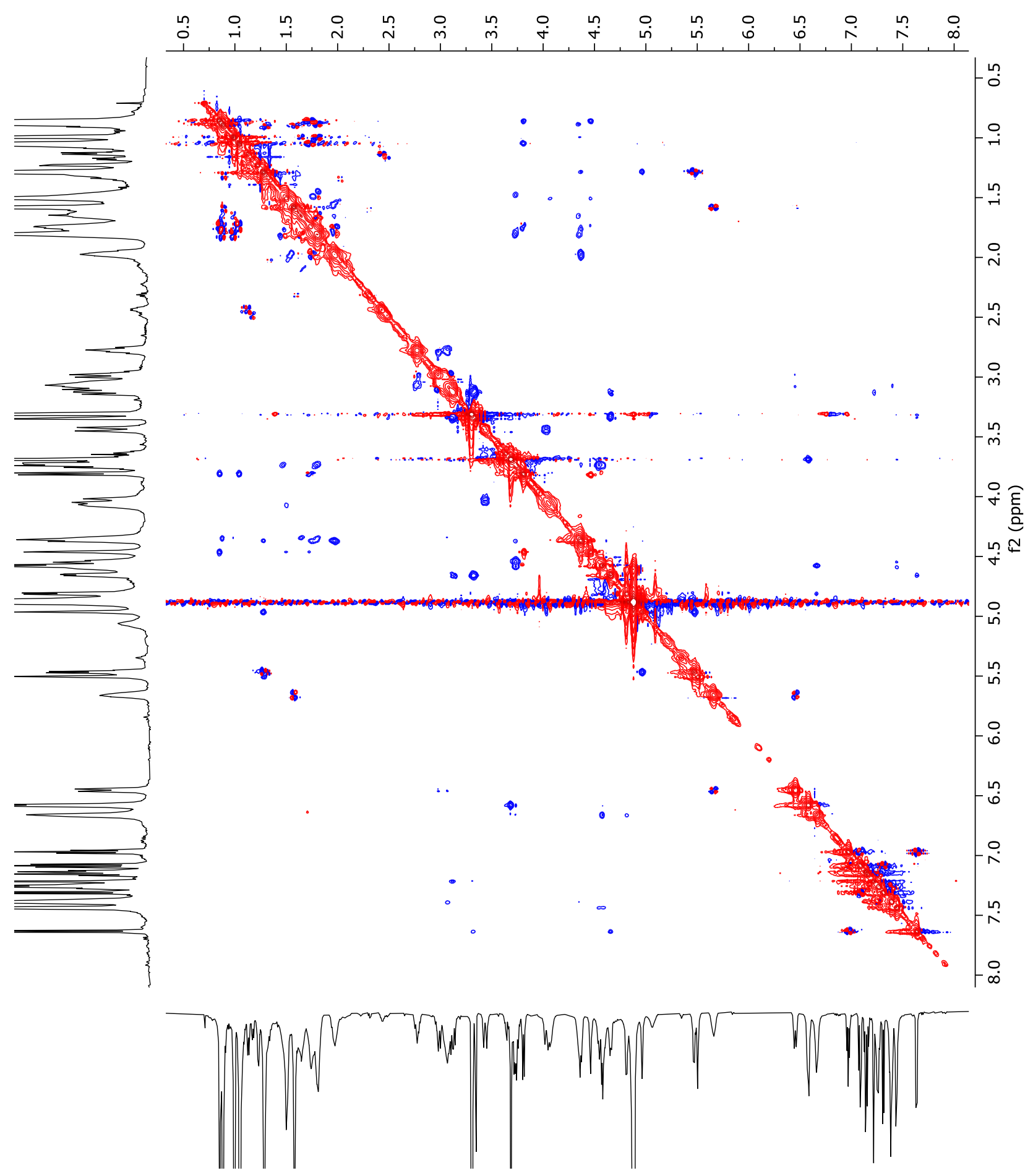


Figure S17. (-)-HRESIMS of compound 1.

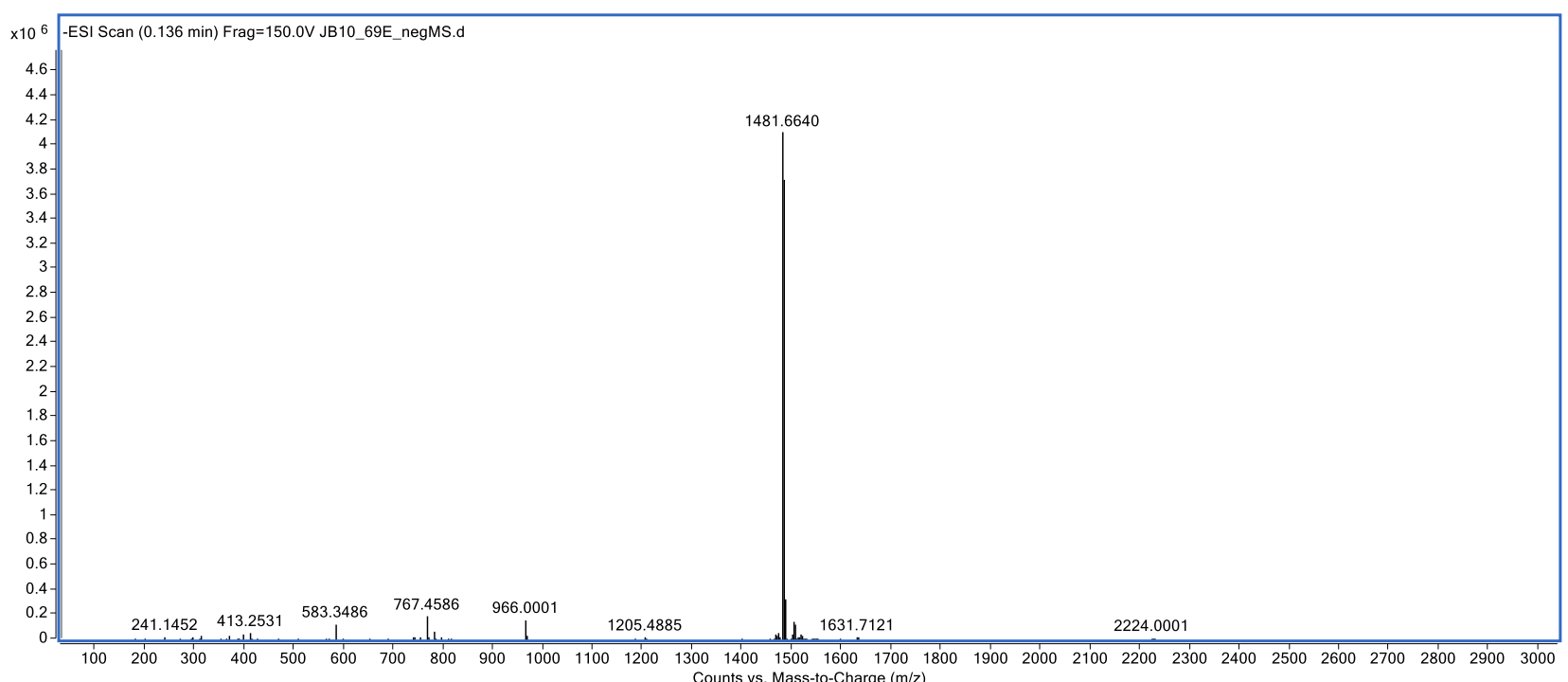


Figure S18. (-)-HRESIMS of compound 4.

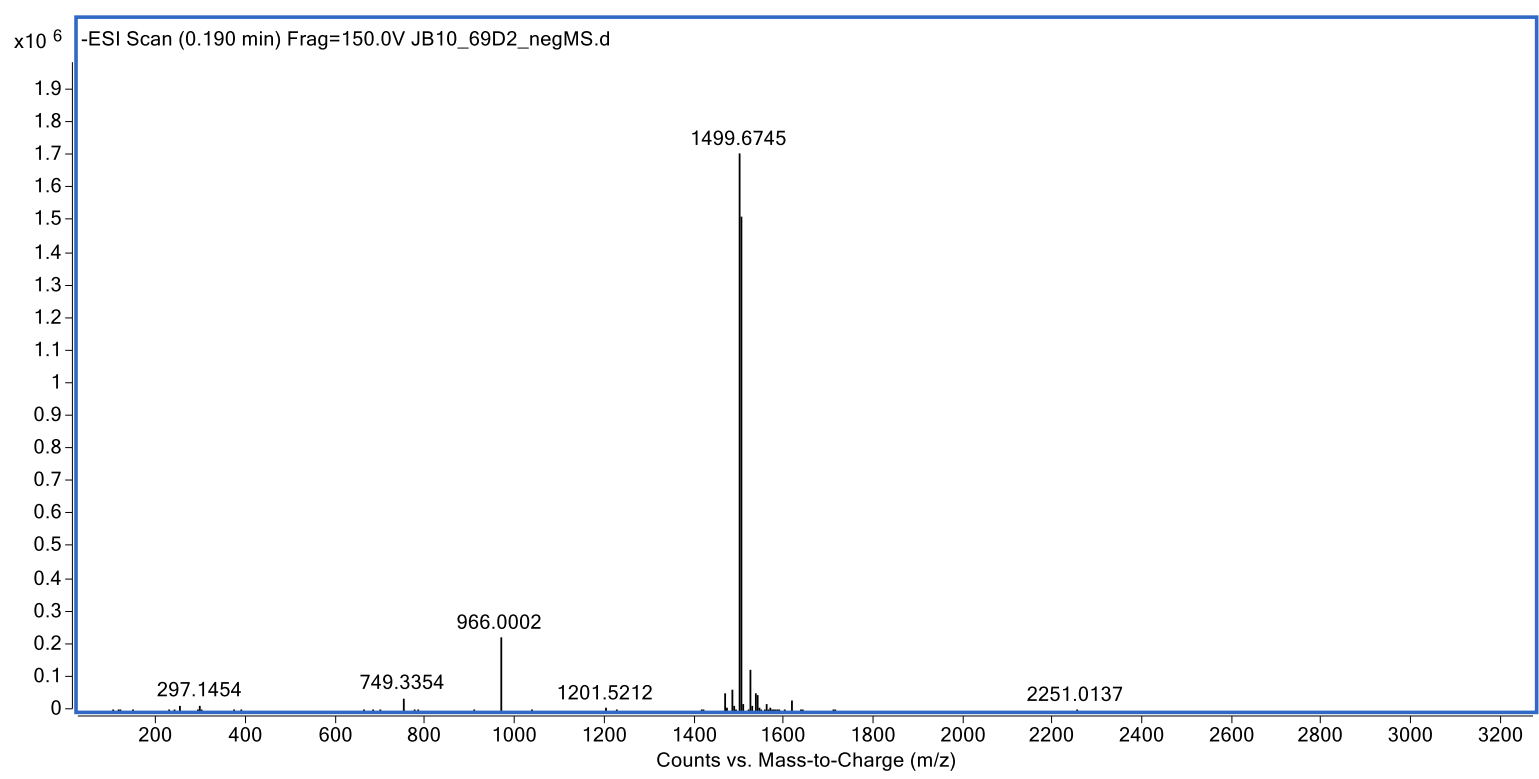

Figure S19. (+)-HRESIMS/MS of compound 6 (hydrolyzed compound 4).

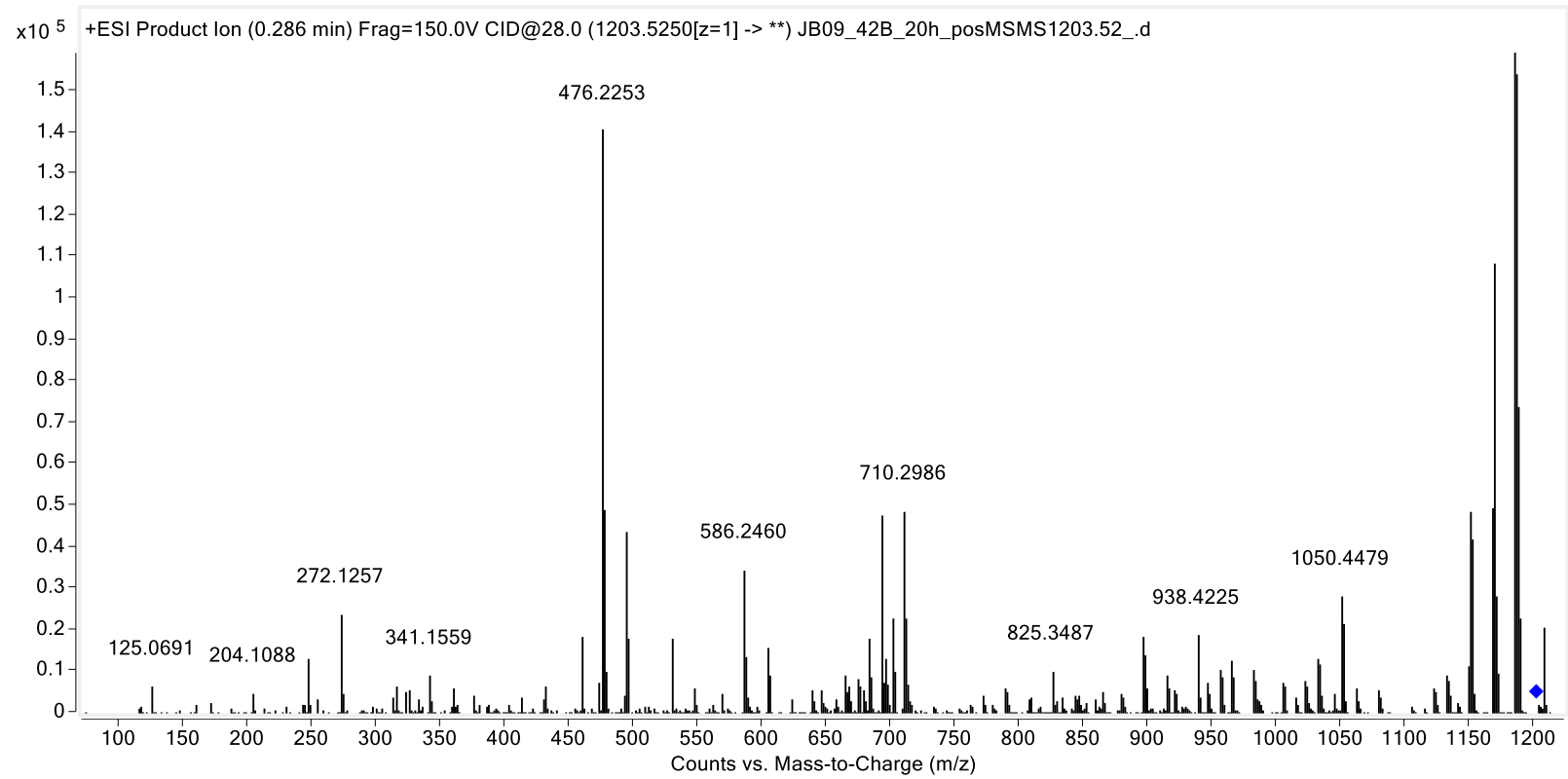


Figure S20. UV/Vis spectrum of 4.

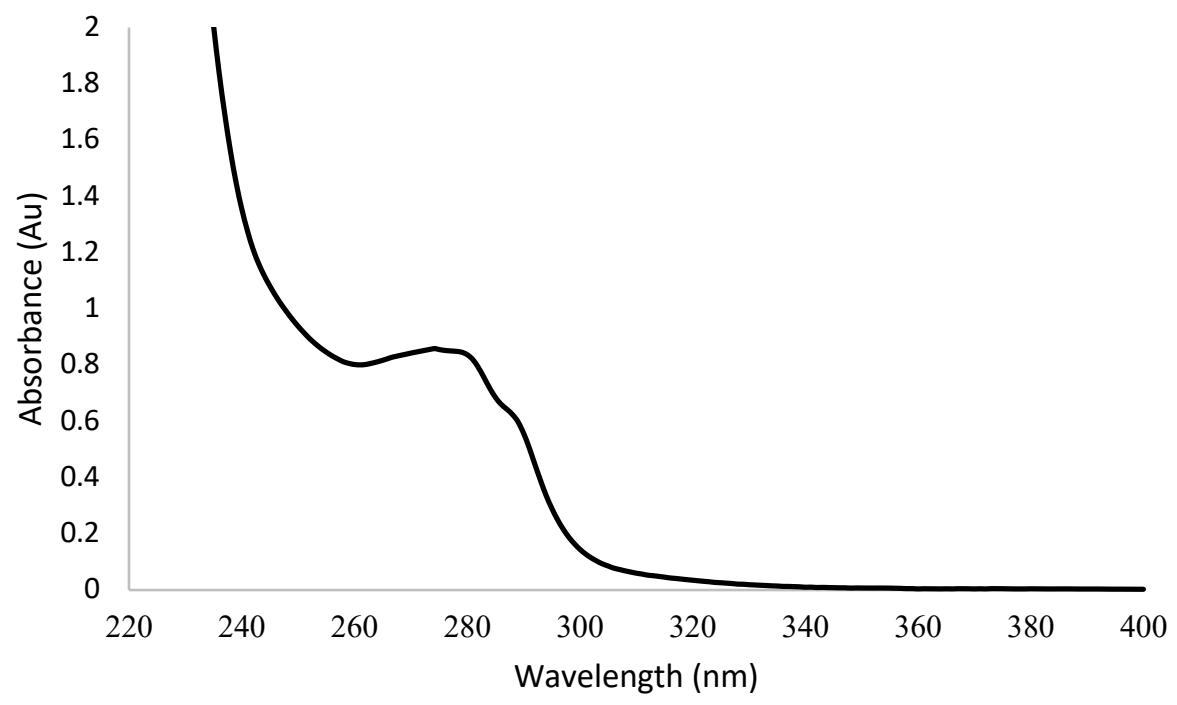


Figure S21. (-)-HRESIMS of compound 5.

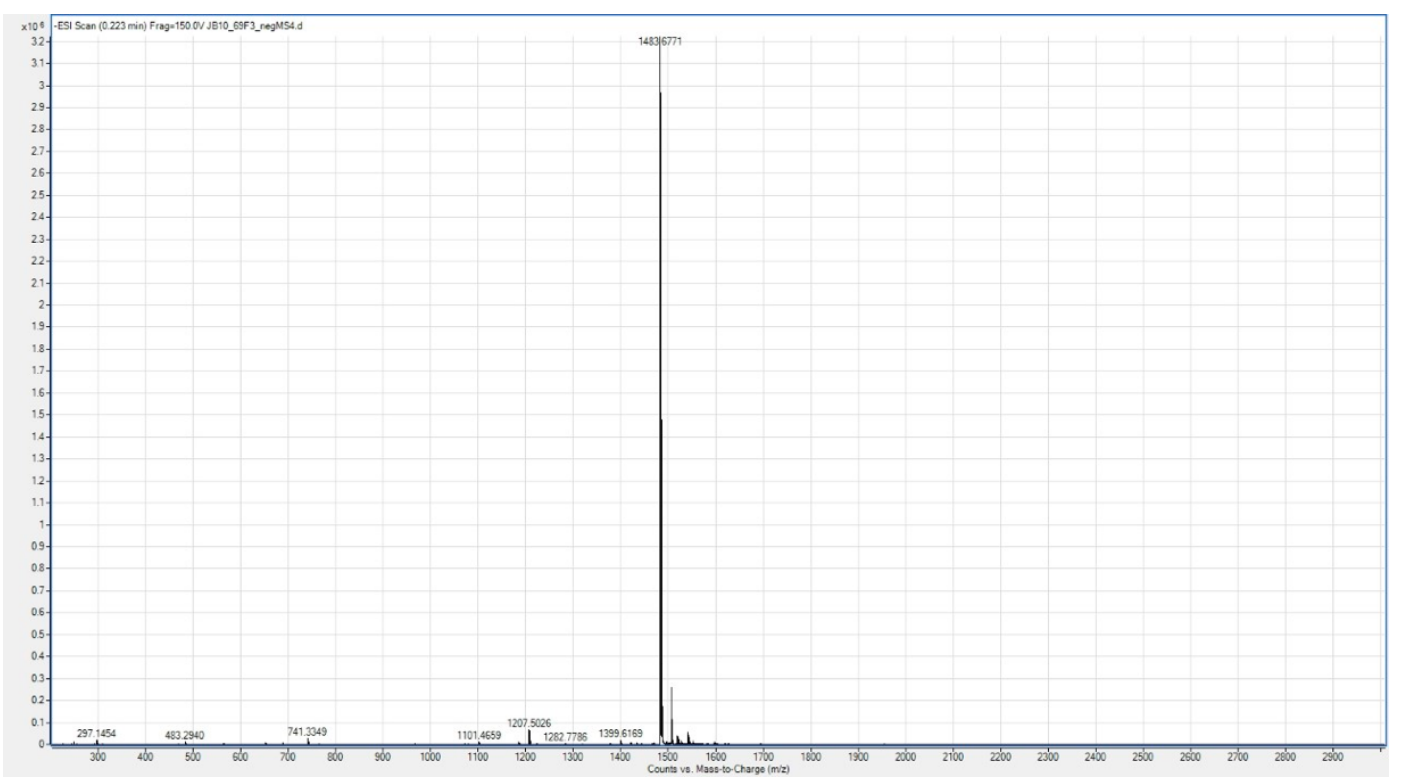

Figure S22. (+)-HRESIMS/MS of 7 (hydrolyzed compound 5).

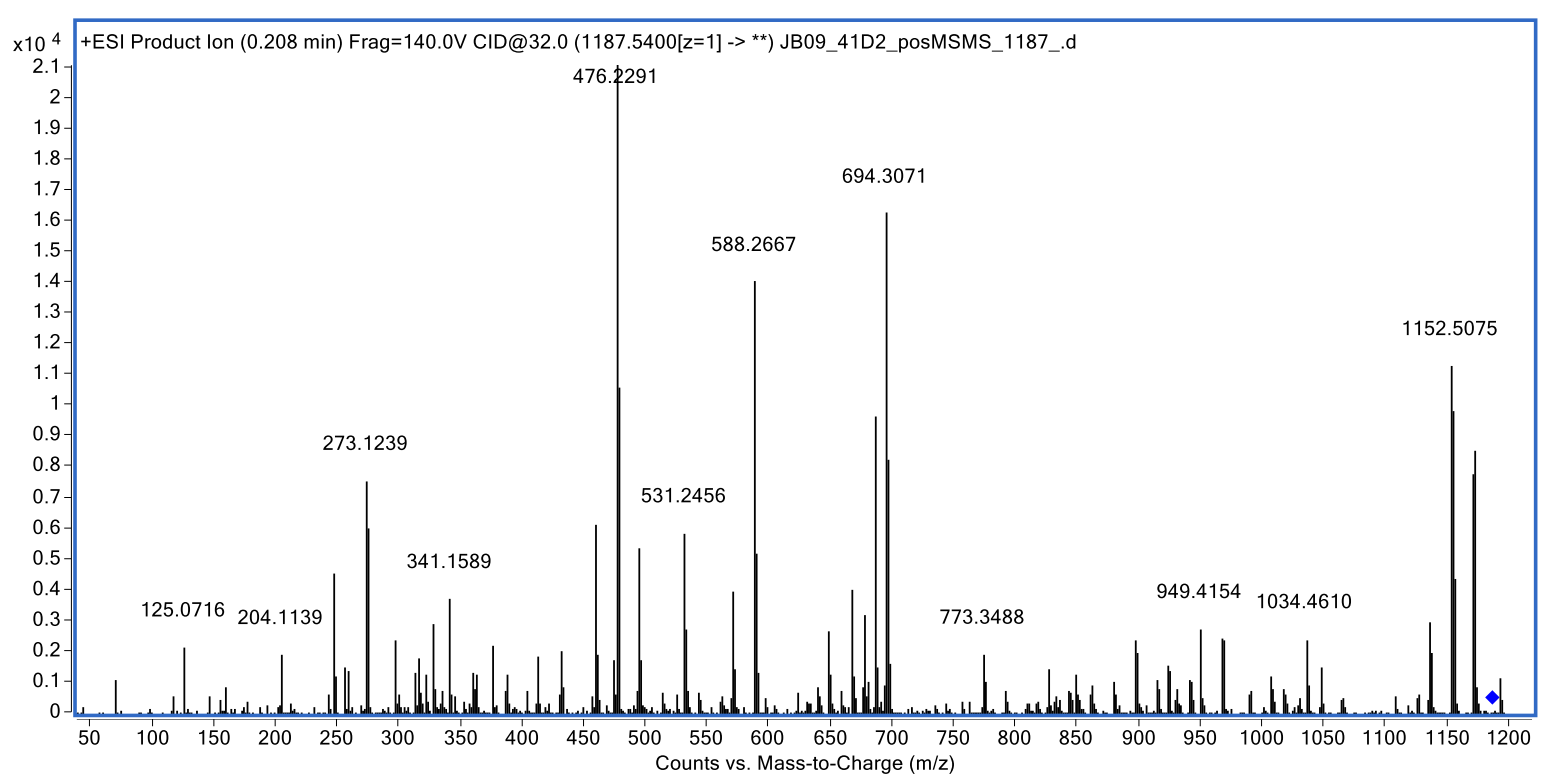


Figure S23. UV/Vis spectrum of 5.

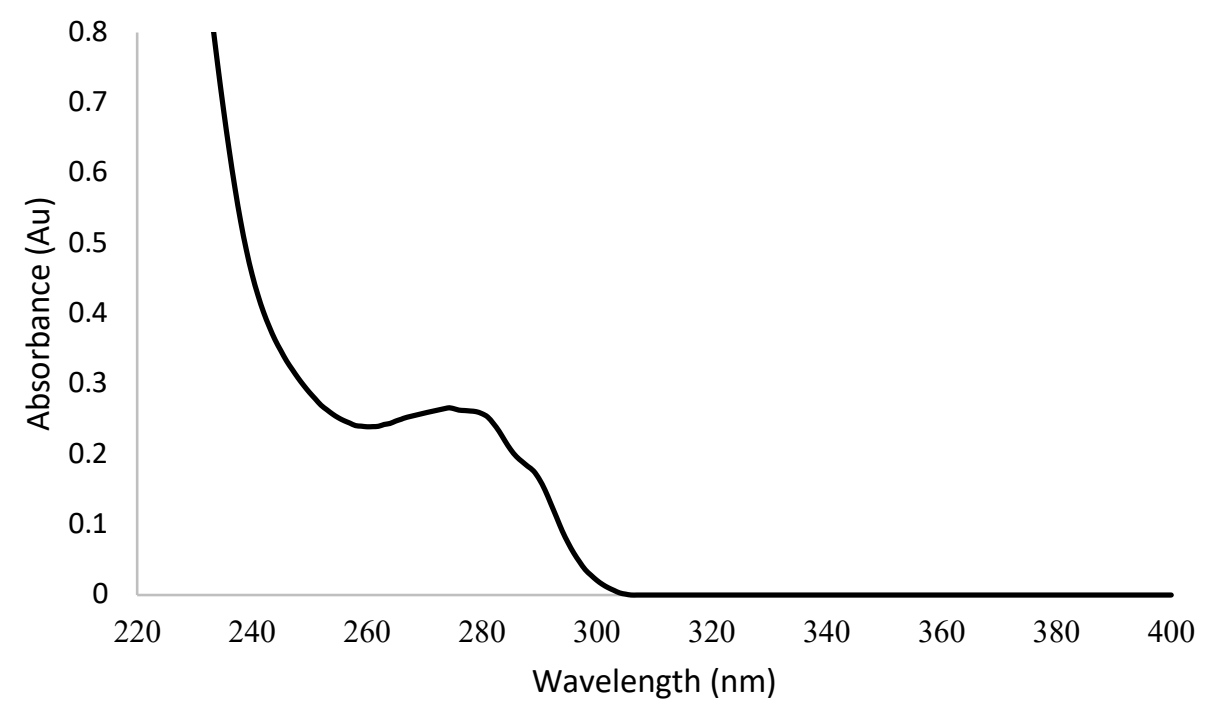


Figure S24. ECD spectrum of 1.

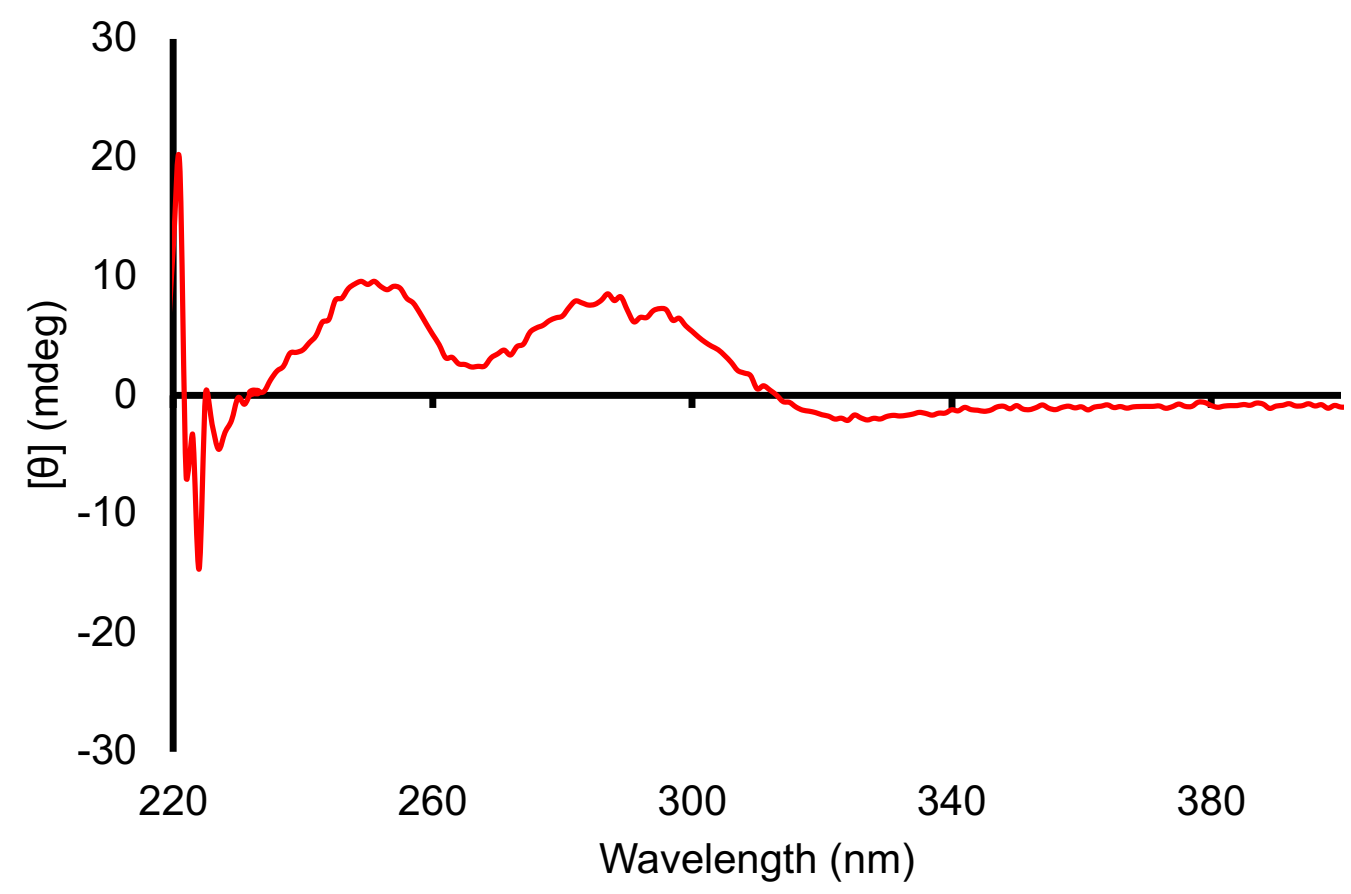


Figure S25. ECD spectrum of 4.

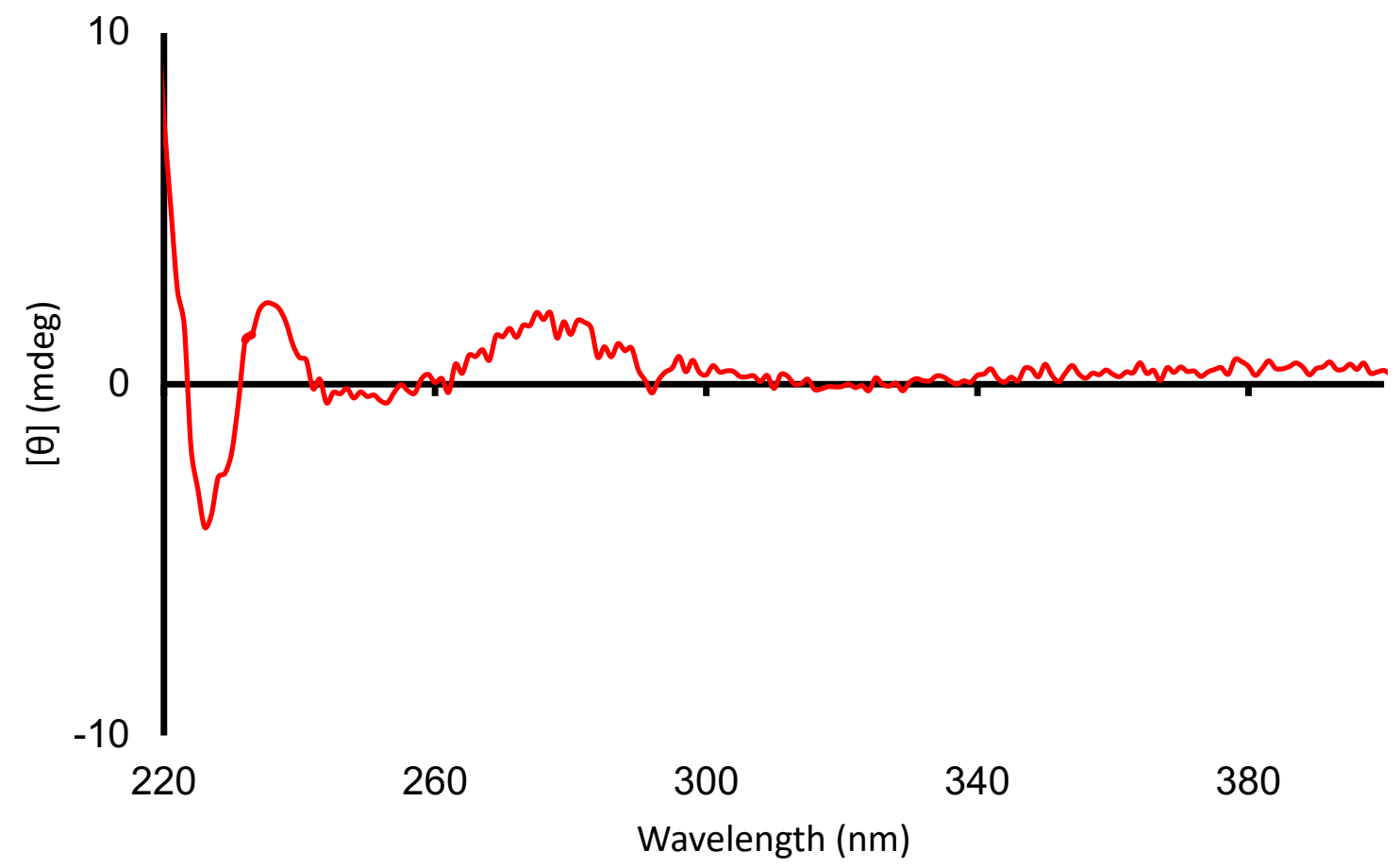

Figure S26. ECD spectrum of $\mathbf{5}$.

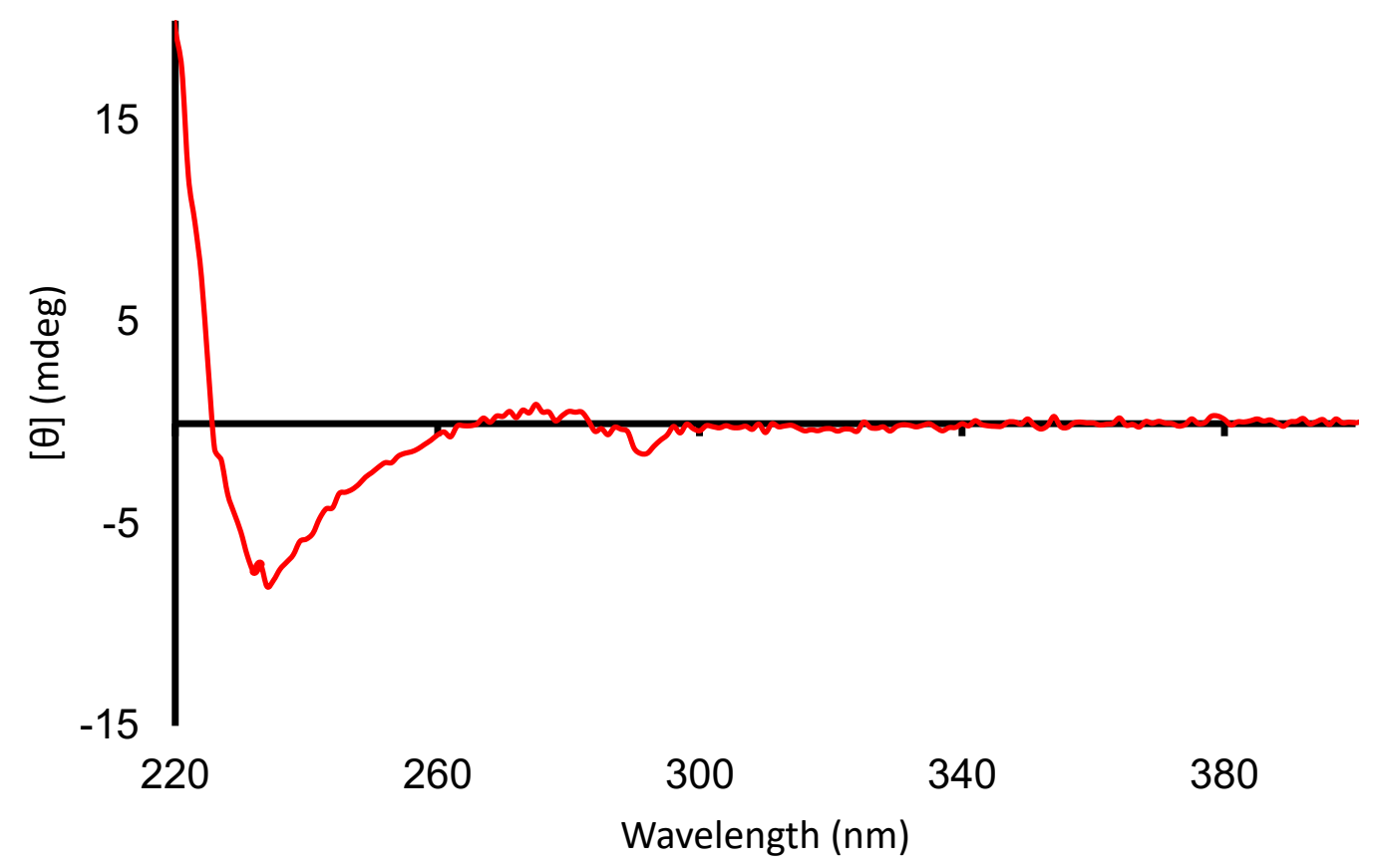

